\title{
الطائفية وسبل مواجهتها
}

\section{عبد الله إبراهيم زيد الكيلاني}

الملخص

يتناول هذا البحث بيان وجهة النظر الإسلامية في مسألة اختلاف الملل والنحل، وأهمية بناء الفكرة الجامعة

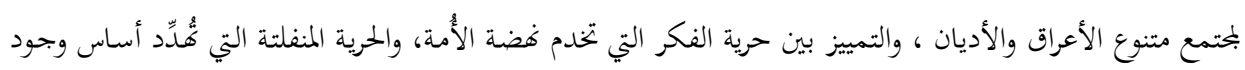

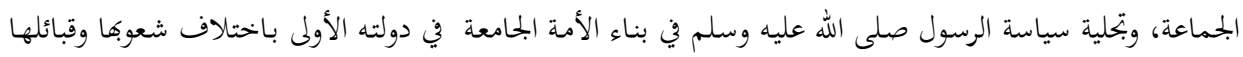

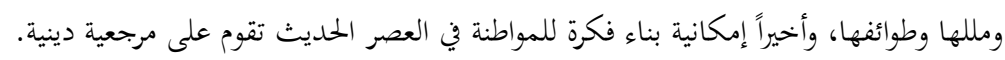

وتعرض الدراسة لبعض النماذج التراثية والمعاصرة للتعامل مع الاختلاف الفكري والسياسي وتناقش إمكانية الإفادة من بتحارب الأمم في بناء فكرة جامعة.

الكلمات المفتاحية: الطائفية، المواطنة، الدولة، الطائفة، الاجتماع الإنساني.

\section{Sectarianism and ways to confront it}

\begin{abstract}
This study deals with the Islamic viewpoint on issue of differences among various sects and denominations, the importance of building the universal idea of a society of different races and religions, and the distinction between freedom of thought that serves the nation's progress and the uncontrolled freedom that threatens the foundation of the group existence. The Study also reveals the policy of the Prophet (peace and blessings of Allah be upon him) in building the universal Ummah of its first state composed of different nations, tribes, sects and denominations. Finally, it discusses the possibility of building a contemporary idea of citizenship based on religious authority.

The study presents some traditional and contemporary models that deal with intellectual and political differences and discusses the possibility of benefiting from the experiences of various nations in building an inclusive idea.
\end{abstract}

Keywords: Sectarianism, Citizenship, State, Community, Human society.

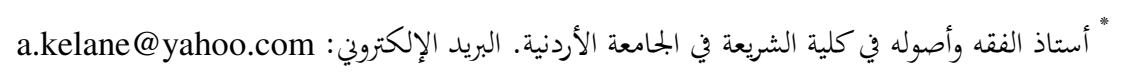

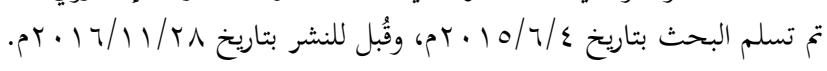




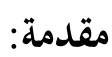

ينطلق بعض دارسي مسألة الطائفية من الخلط بين المفهوم الديني والمفهوم السياسي،

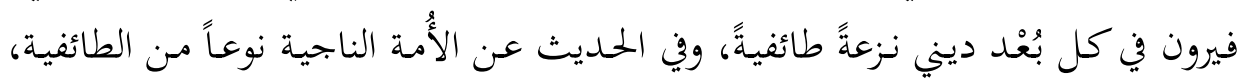

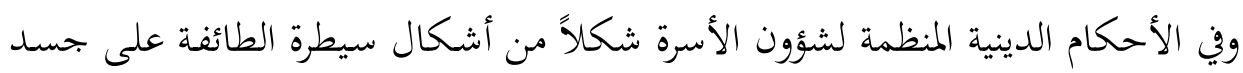
الأننى، ' كما في تحريم زواج غير المسلم من المسلم.

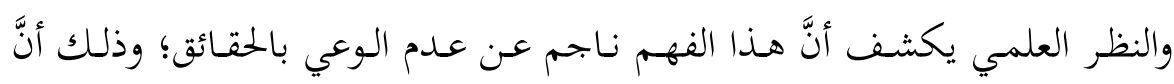

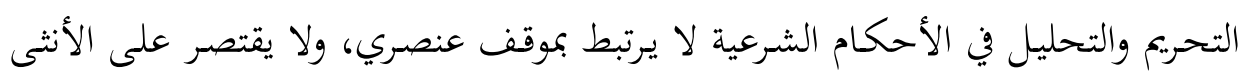

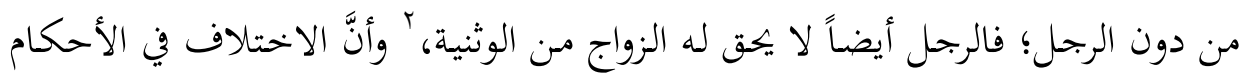

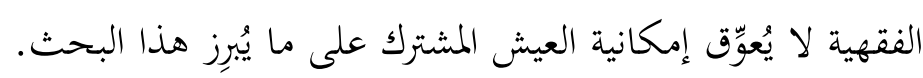

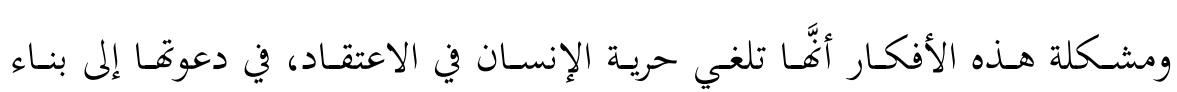

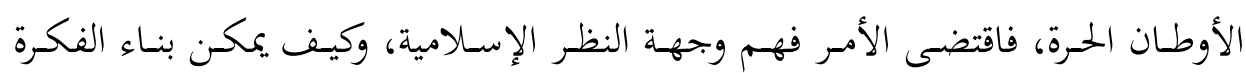

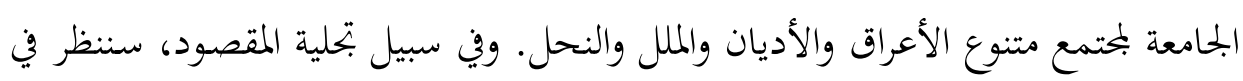
مناحي هذه المسألة، بدءاً بفهم الاجتماع الإنساني وقوامه. والقضية التي يهدف البحث إلى معالجتها لا تتوقف فقط عند حرية الرأي المكفولة

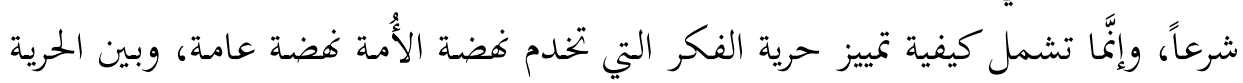

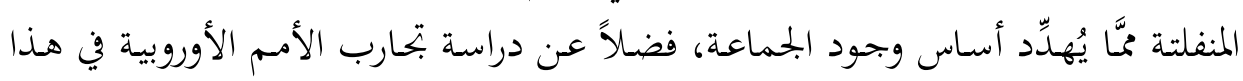

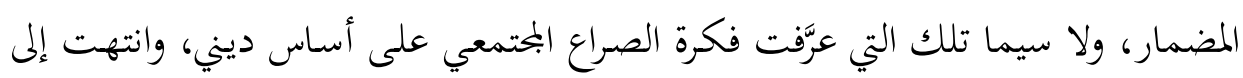

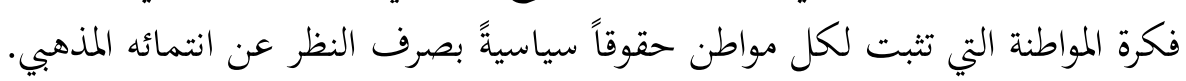

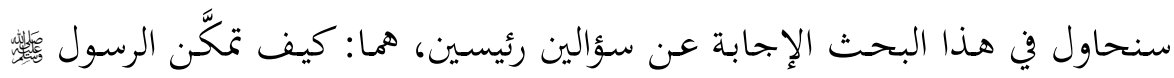

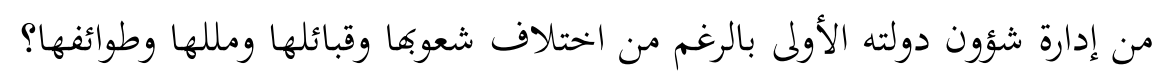

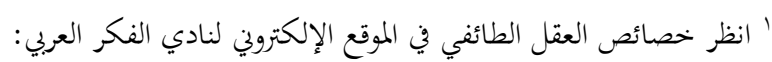
rhtp//www.nadyelfikr.com r انظر خصائص النقاش السوري عن الطائفية في الموقع الإلكتروني لصحيفة الحياة، مقال ياسين الحاج صالح، وتاريخ

- http://www.alhayat.com/Opinion/Writers/9141776/

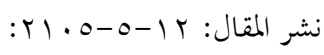


والسؤال الثاني: كيف يمكن بنـاء فكر المواطنة في دولة إسلامية تقوم على أسـاس

ثم سنعمل على دراسة فكرة الجويني في التعامل مع أهل البدع بوصفها نموذجاً تراثياً،

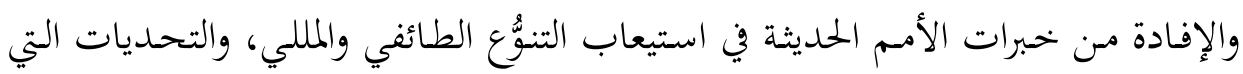

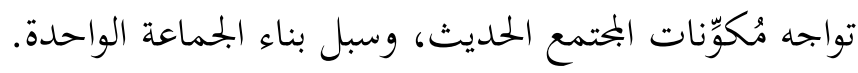

\section{أولاً: قوام الاجتماع الإنساني}

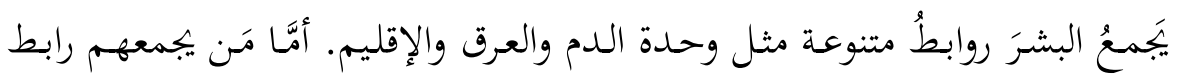

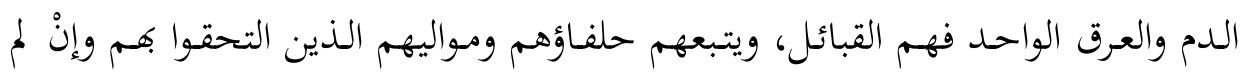

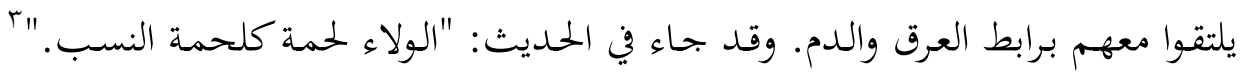

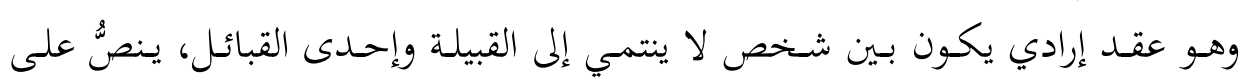

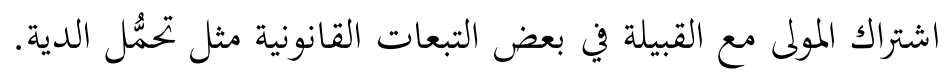

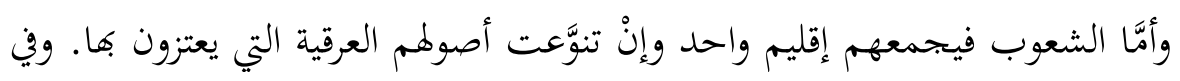

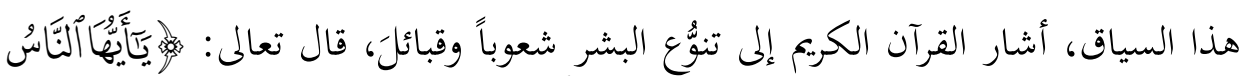

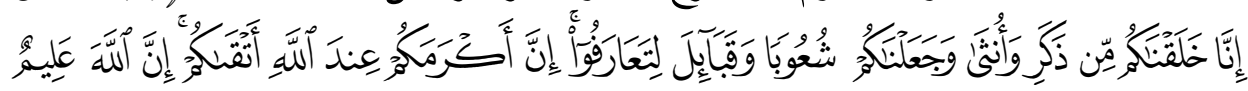

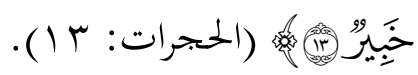

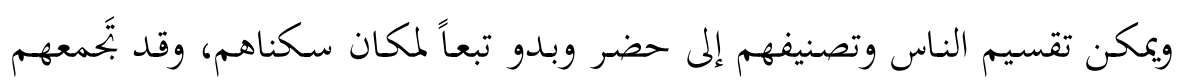

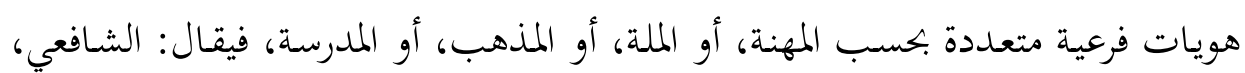
والأزهري، وهكذا.

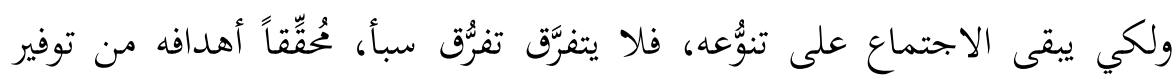

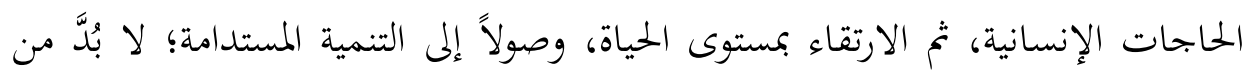

- الشافعي، أبو عبد الله حممد بن إدريس بن العباس بن عثمان. المسند، بيروت: دار الكتب العلمية، . . 1 اهـ،

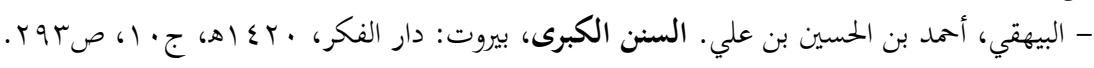




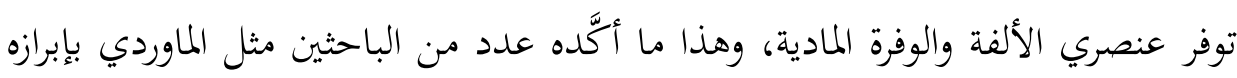

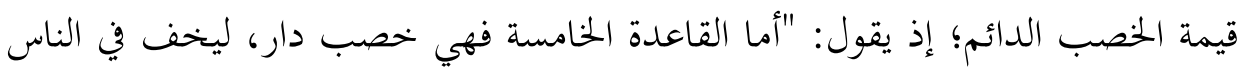

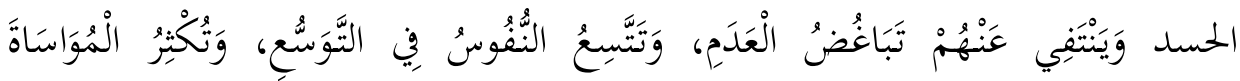

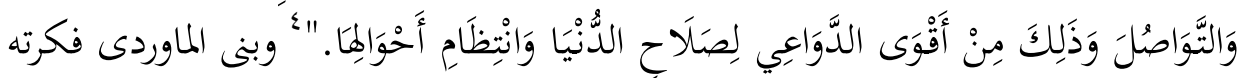

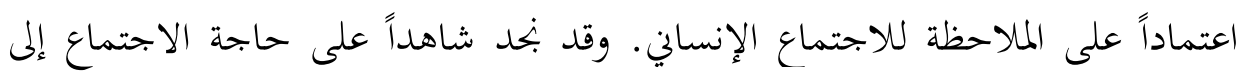

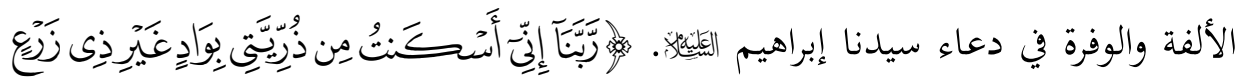

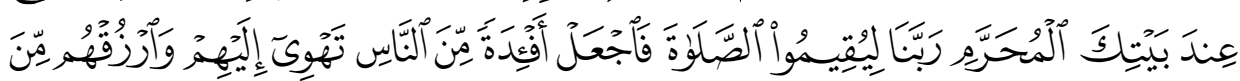

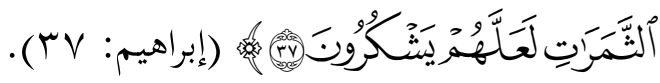

\section{ثانياً: أمراض الاجتماع الإنساني التي تحول دون تحقيق التنمية والارتقاء}

يعرض للاجتماع الإنساني أعراض تُعطّل وظائفه فيما يخص توفير الحاجات وتحقيق

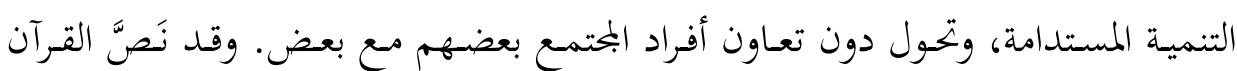
على عدد منها، مثل: الأعرابية، والزعامات الطفيلية (الزنيم)، والطائفية.

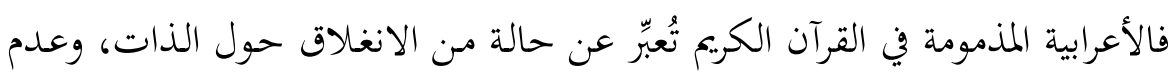

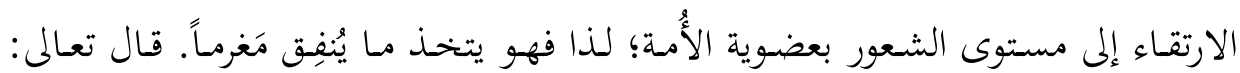

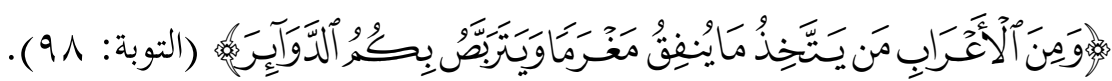

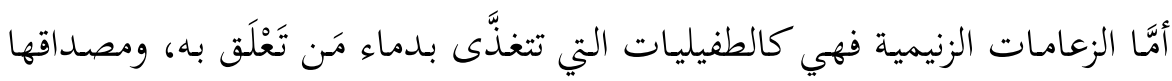
الزعامات التي تتكسَّب بسرقة مكتسبات التنمية، والاستئثار بثروات البلاد.

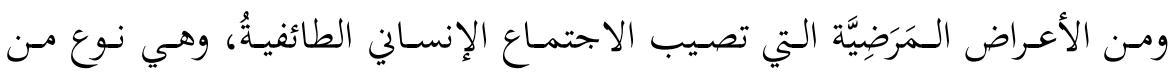

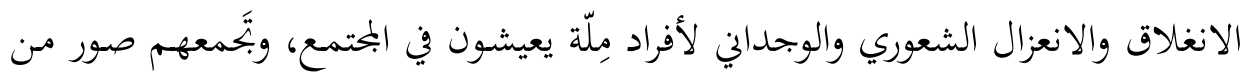

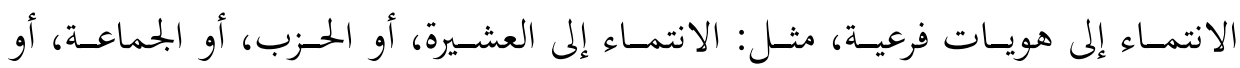

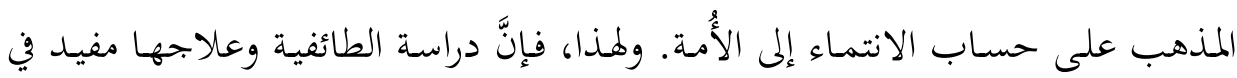

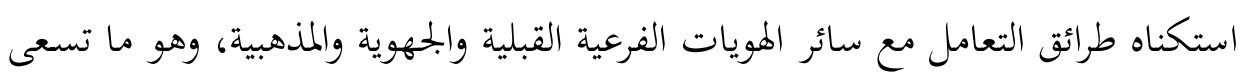


إليه الدراسة بفهم هذه الظاهرة، وبيان وسائل دمج الجماعات المتنوعة، وصولاً إلى مفهوم

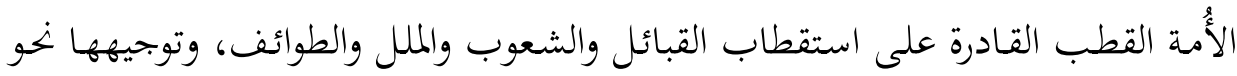
أهداف تنموية تُُقِّق العمران.

\section{ثالثاً: تعريف الطائفة}

الطائفة لغةً تأتي بمعالٍ عدَّة، منها: الجماعة من النـاس، وقد تُطلَق على الواحد،؛

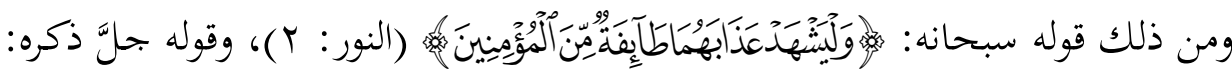

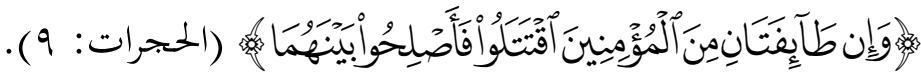
وتأتي أيضاً بمعنى أخص، هو : الفِرقة التي يجمع أفرادها مذهب واحد، مثل الطوائف

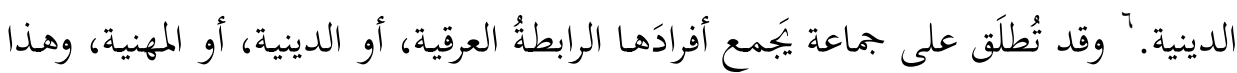

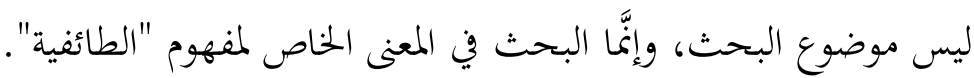
والقبيلة والعشيرة والملة كلها طوائف بالمعنى اللغوي، يجمعها العرق أو الدين. غير أنَّ

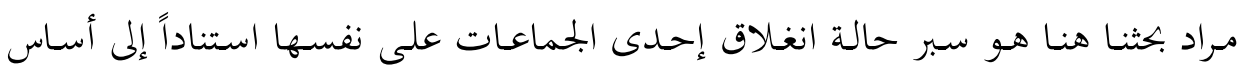

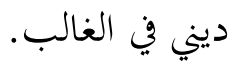

فلفظ "الطائفية" هو مصدر صناعي، والمصدر الصناعي يُطلَق على كل لفظ (جامد

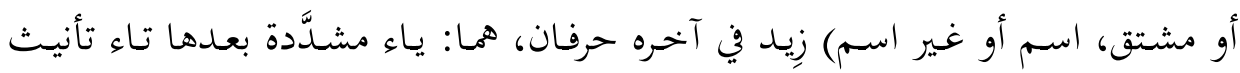

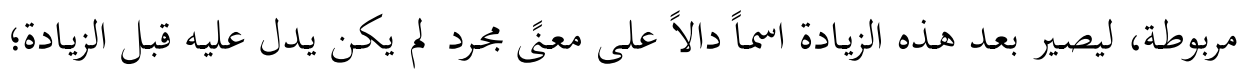

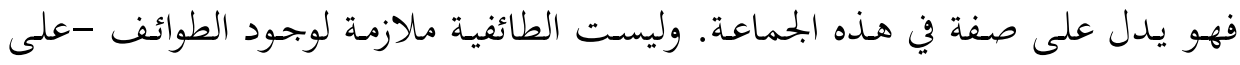

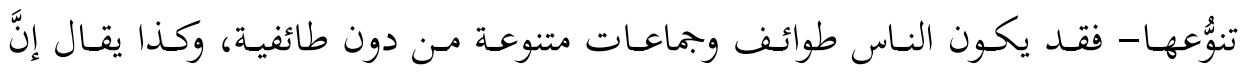

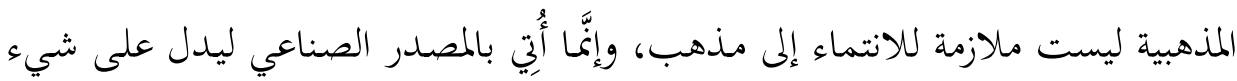
إضافي في اللفظ الذي صُنِع منه.

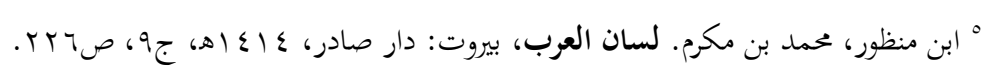

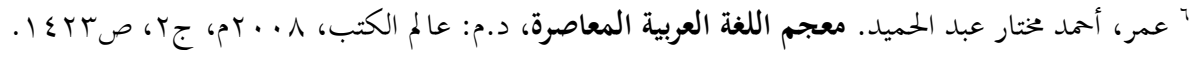


فـالمعنى الـذي قُصِـد الدلالـة عليـه مـن المصـدر الصـناعي هـو انغـلاق الطائفـة على

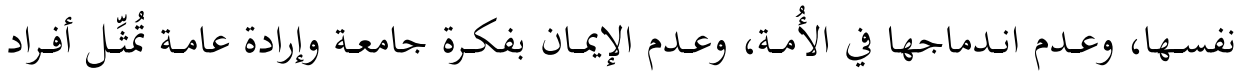
البحتمع . فالطائفيـة يجمعها طلب الامتيـازات من الجماعـة، ويظهر ذلك جليـاً في المواقع السياسية العليا، حيث تُخصَّص حصص للطائفة، وتحظى بامتيازات خاصة من مكاسب التنمية.

أمَّا فكر الأُمة فيقوم على أساسِ يُحِقِق المصلحة لأفرادها جميعاً في مقابل المراضاة التي تعتمدها المفاهيم الطائفية.

وكذا فهي نوع من العنصرية القائمة على أساس طائفي ومذهبي، وليست حديثاً عن

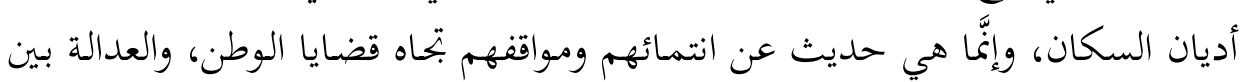
الخلق، وهي بذلك تتناول جانباً اجتماعياً وسياسياً وقانونياً يستند إلى أساس ديني. والعصسبية الطائفيـة لا يُقرِّهـا النظر المصـلحي الرشـيد، وهـي لا تُوائِم سُسنن العمـران

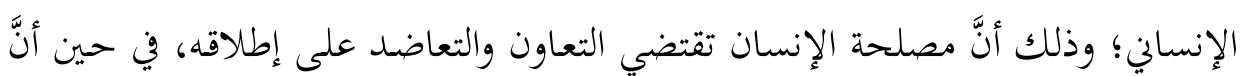

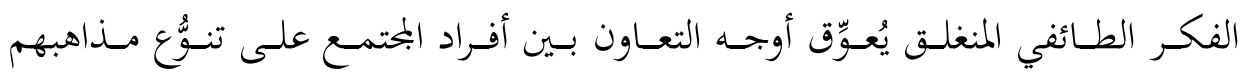
وطوائفهم.

وهنـا، لا بُدَّ أنْ نُنبِّه على أنَّ دراسة الطائفيـة والمذهبيـة ينبغي أنْ تنطلق مـن دراسـة

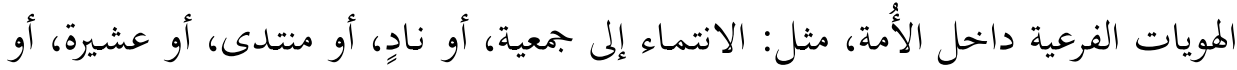
مذهب.

والأصل أنْ يُنَر إلى هذا الانتماء بوصفه أمراً بدهياً طبيعياً؛ لأنَّ الإنسان يولد في أسـة، ويصسلي في مسـجد، أو معبـد بحسـب دينـه، ويـدرس في مدرسـة، ويلعـب في نـادٍ، ويمارس أنشطة ثقافية في منتدى، ويشتري من متجر، فيحصل نوع من الإلف والانتماء

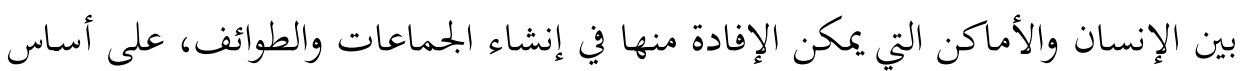

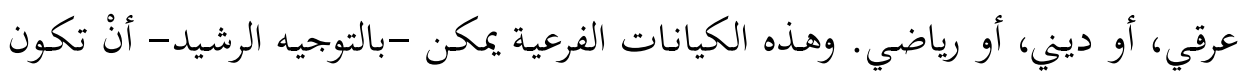

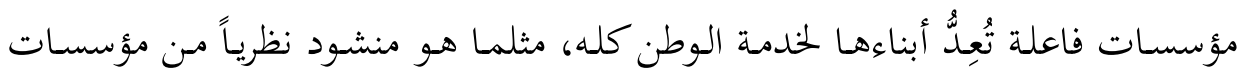

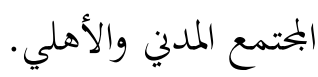




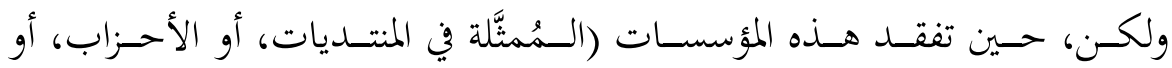

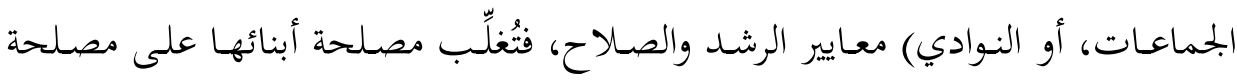

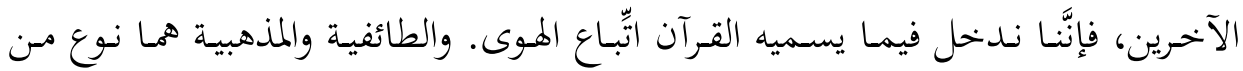
الهوى.

والقرآن الكريم سعى إلى حماية الطائفة من الطائفية، والمذهب من المذهبية الضيقة،

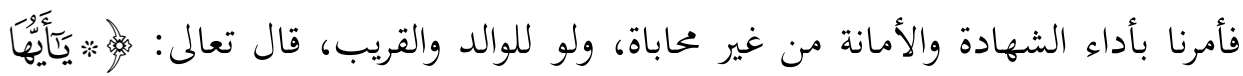

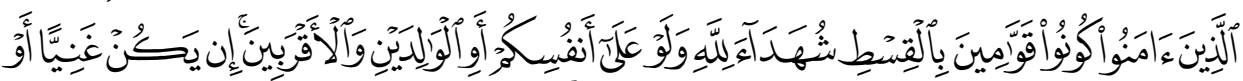

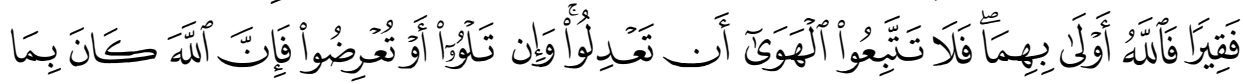

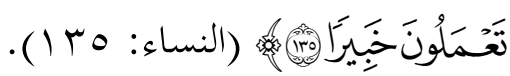

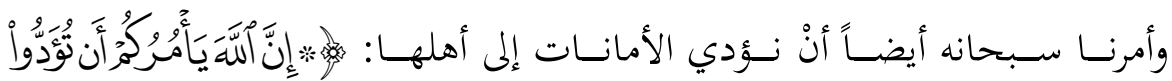

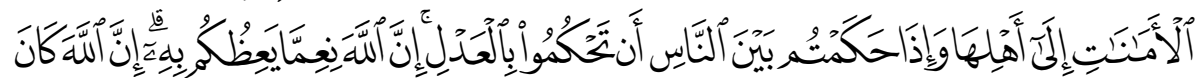

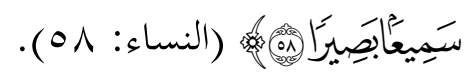

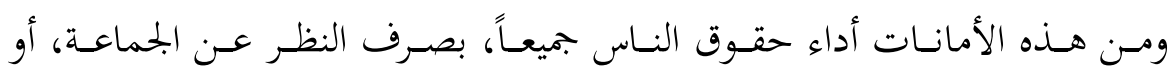

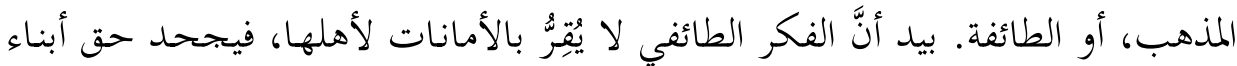

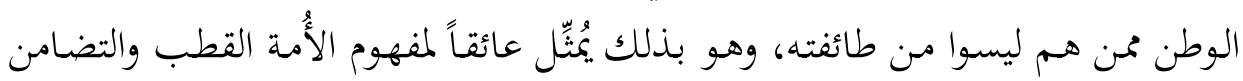

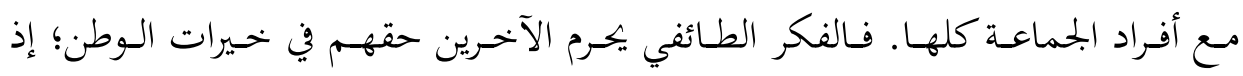

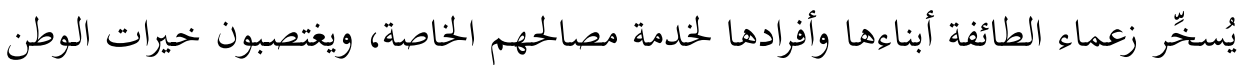

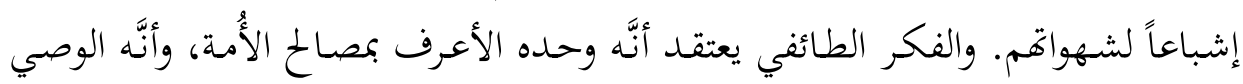

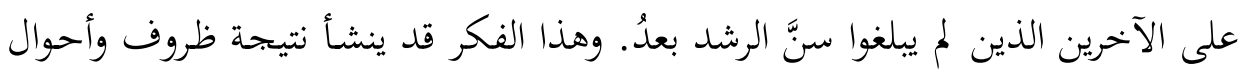

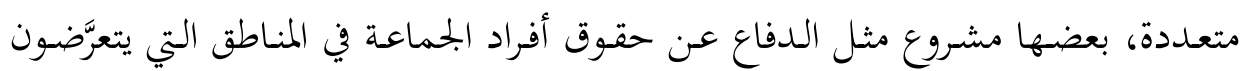

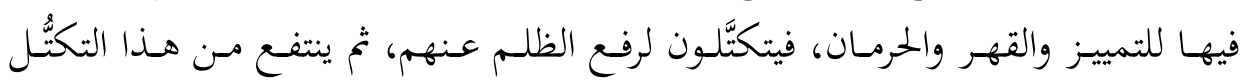

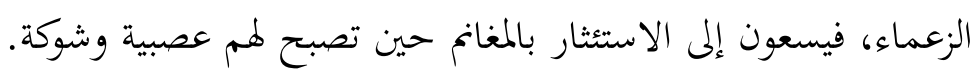

والفكـر الطـائفي -شـأنه شـأن جميع العصبيات البدائيسة التي لا ترتقي إلى مفهوم

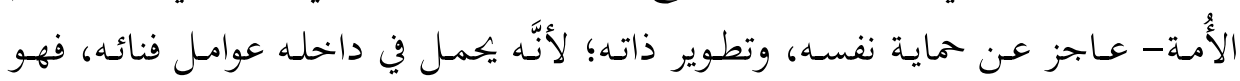


يظهر أولاً لحمايـة الطائفـة، فتقـوى العصبية، وتتحقَّقق لهم الشـوكة، ثم حسين يهـدث لهـم

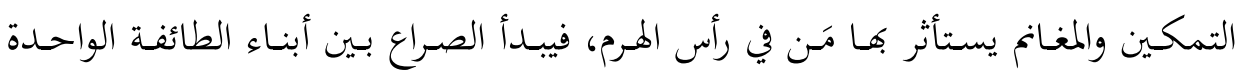
نفسها، ويزداد الشرخ مع تعمُّق شعورهم بالحرمان، واستئثار فريق ما بالملكاسب، بالرغم مـن التسـاوي في سـبب الاستحقاق؛ فيجــع الأمسير أنـف أبنـاء عمومتـه، وأنـف أتبـاع عصبيته الطائفيـة. وهنـا يسعى قادة الطائفة إلى تعويض النقص باستتباع بعض محرومي

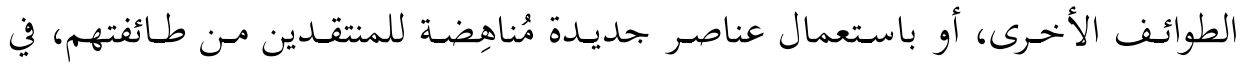

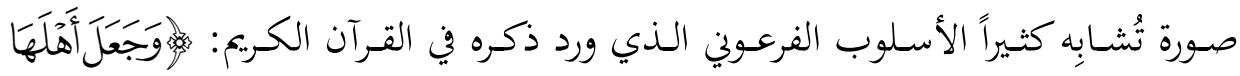

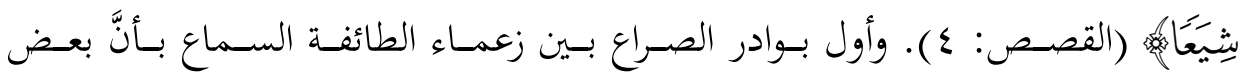
المُققَّبين من زعيم الطائفة قد انتحروا بإطلاق عدة رصاصات على أنفسهمب!، ثم يكثر عدد المنتحرين.

أمَّا الأعراض الحمرَضِيّة للفكر الطائفي فتتمثَّل في صور وأشكال عـدَّة، أبرزهـا توزيع الثروات والمكاسب والمناصب على الأهل والأقارب والأحباب. ولمَّا كان الفكر الطائفي

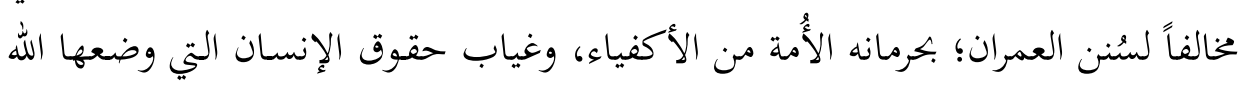

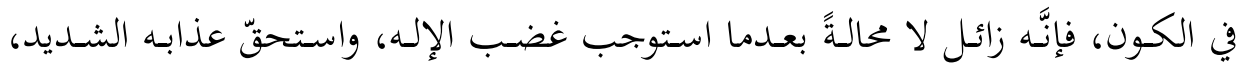

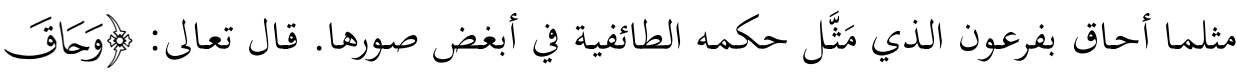

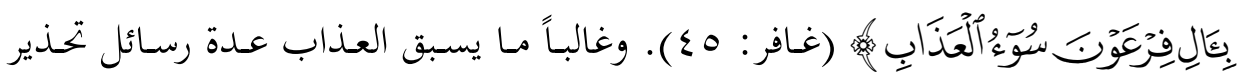
لعلهم يرجعون تتمثل بحركات انتقاد وتمرد. غير أنَّ الفكر الطائفي لا يعي رسائل التحذير ونُنُر الخطر لما فيه من الكِبْر المانع

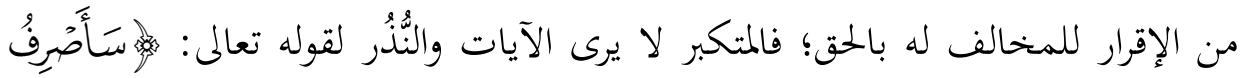

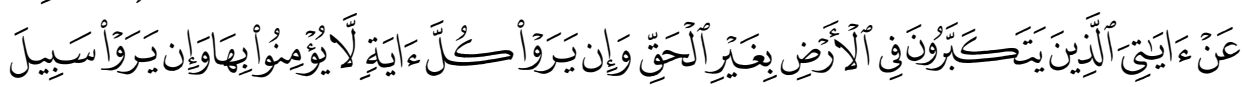

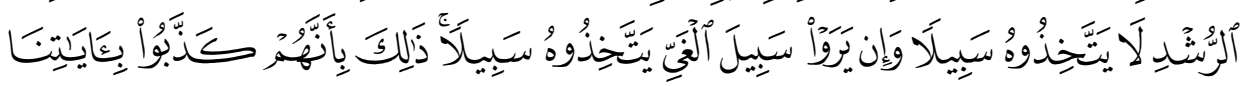

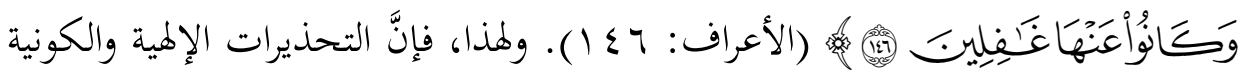
ورسائل النصح لن بُّحِْي نفعاً مع قادة الفكر الطائفي بعد ما زَيَّن لهم الشيطان ما كانوا يعملون، مُصرّين على طغياهم وعتوّهم، حتى يأتيهم الاستئصال بغتةً؛ لقوله تعالى: 


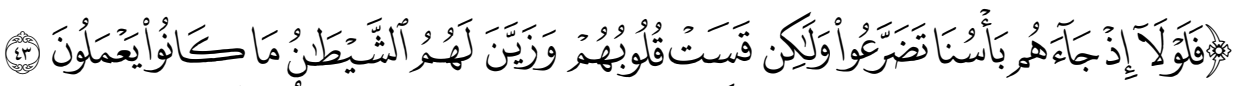

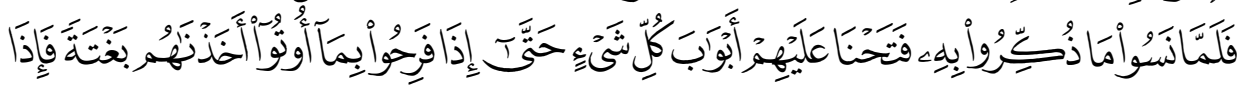

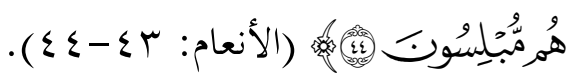

\section{رابعاً: تنبيه القرآن الكريم على حقوق أفراد الأُمة لمنع نشوء الفكر الطائفي}

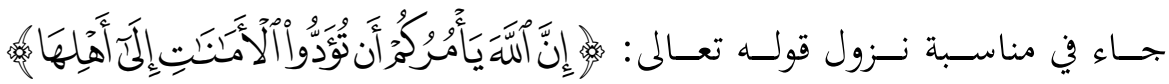

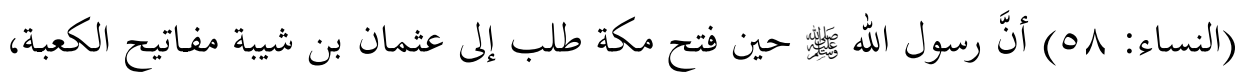
فعرض العباس على رسول الله

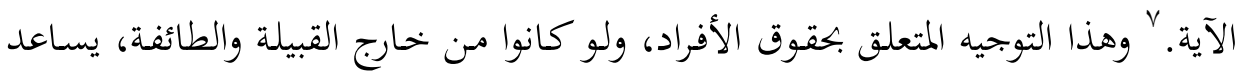

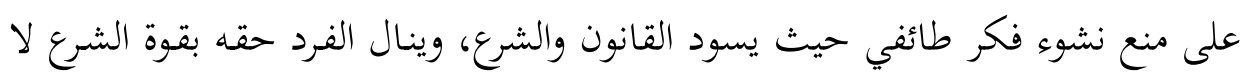
بحماية الطائفة.

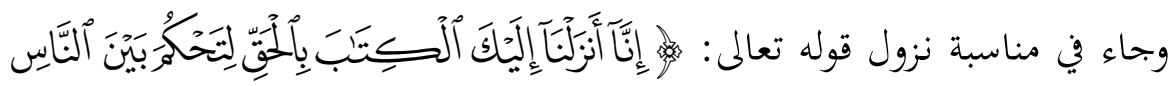

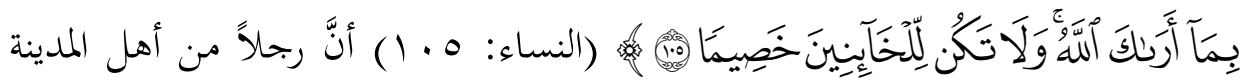

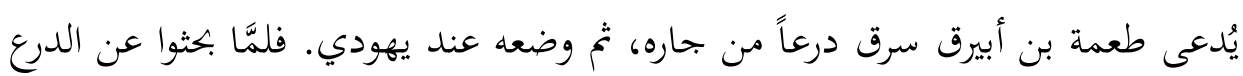

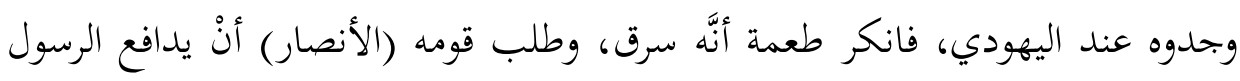

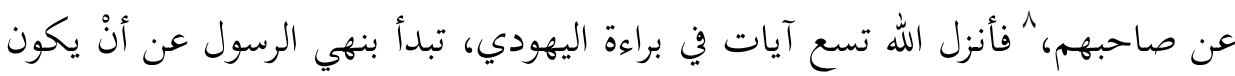

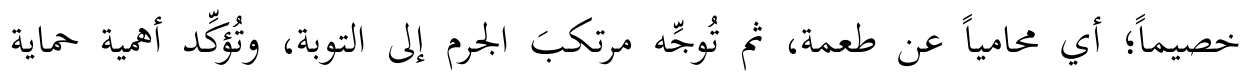

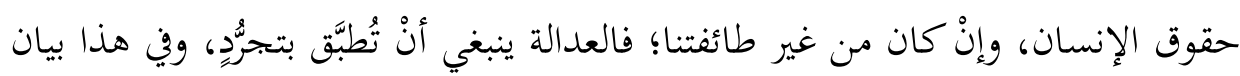

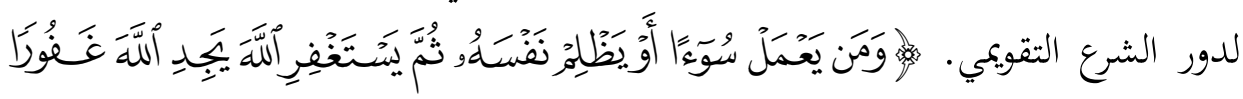

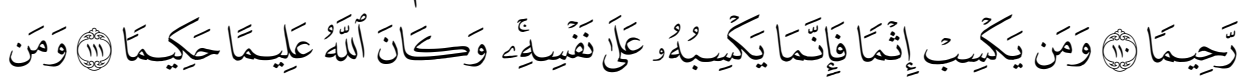

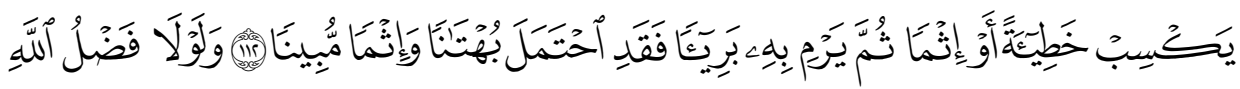
^ابن كثير، أبو الفداء. تفسير القرآن العظيم: تفسير ابن كثير، تحقيق: سامي سلامة، بيروت: دار طيبة، . بـ اهـ،

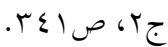

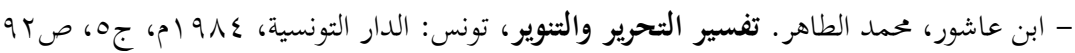

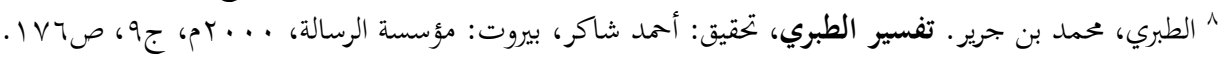




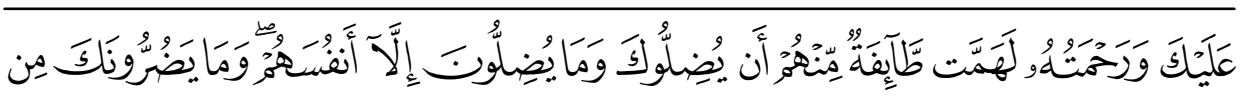

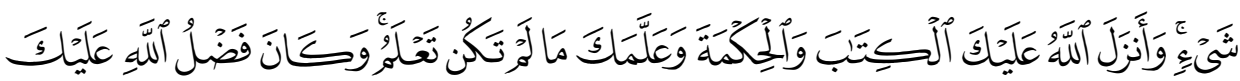

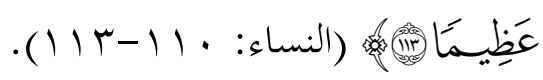

وفي هذا تأكيد للمعنى نفسه من أنَّ قوة الشرع وقوة القانون هي التي تعطي الضعيف حاحف

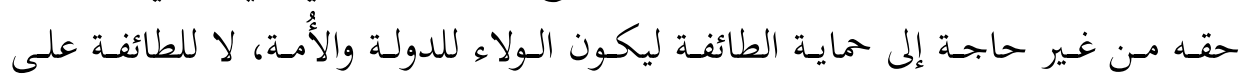

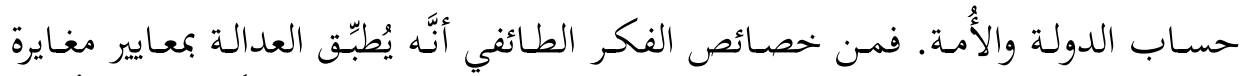

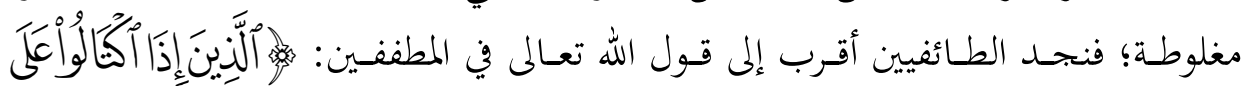

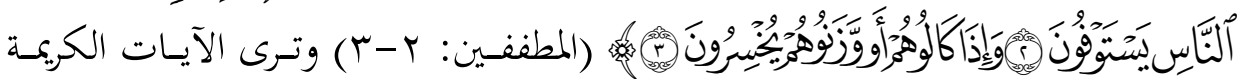

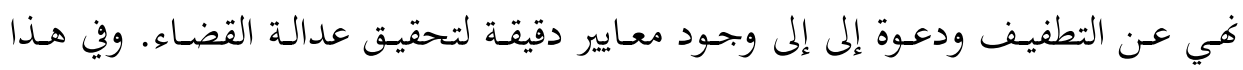

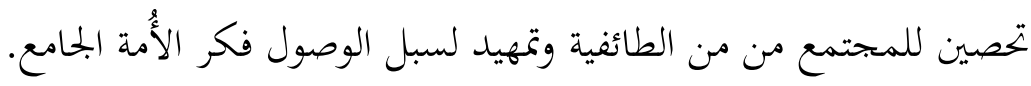
ومما ينبغي التنبيه له أنَّ الفكر الطائفي يُمثِّل أحد عناصر الخطر الذي يتعيَّن تحصين

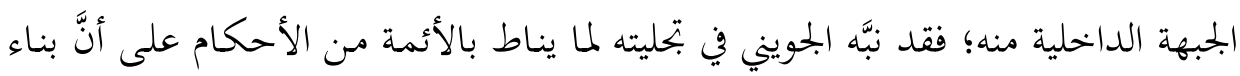

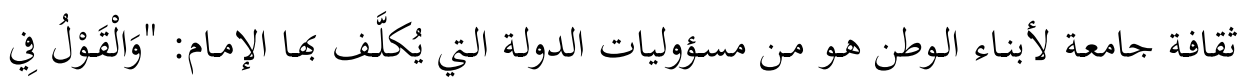

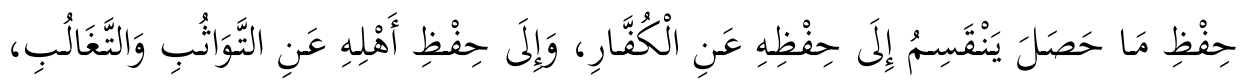

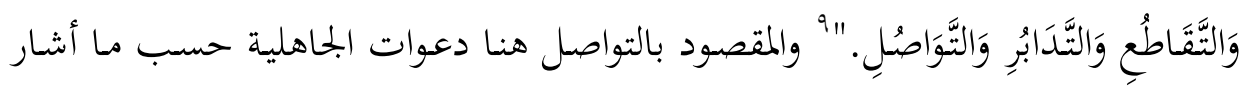

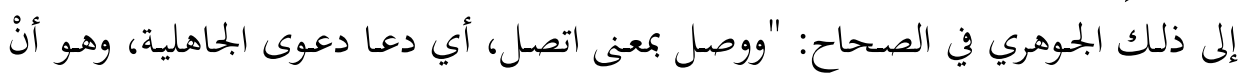

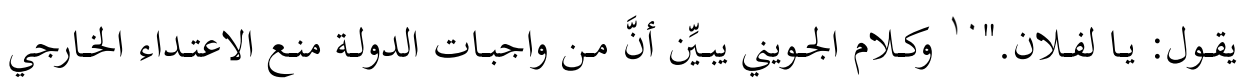

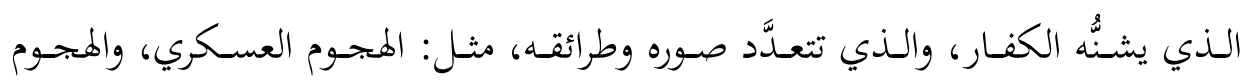

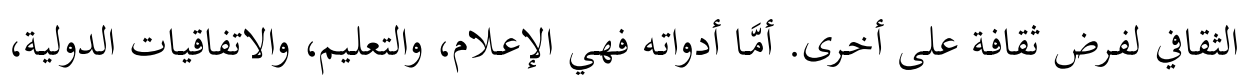

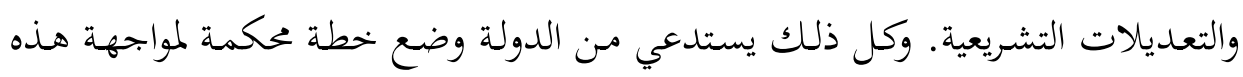

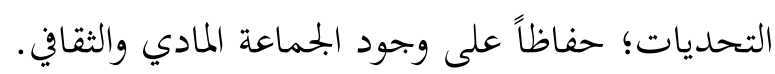
9 الجمويني، عبد الملك بن عبد الله بن يوسف بن محمد. غياث الأمم في التياث الظلم، د.م: مكتبة إمام الحرمين،

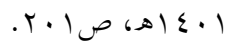

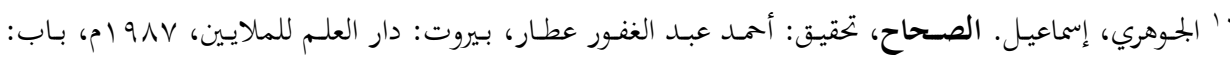


ومسن أوجـه خطر الفكر الطائفي أيضاً اتخـاذ الطائفيين موقفـاً مـن شرعية السلطة

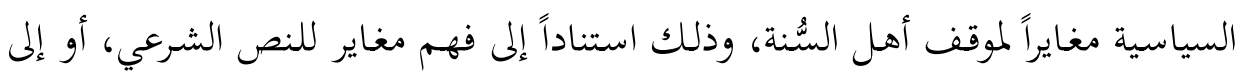

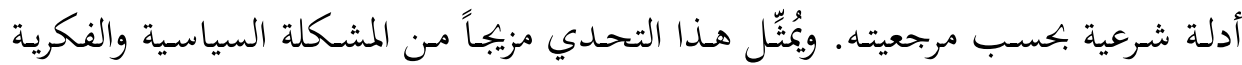

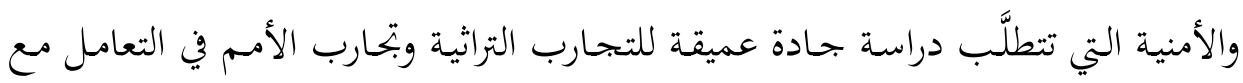

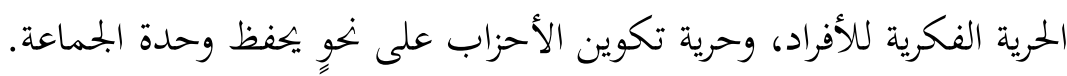

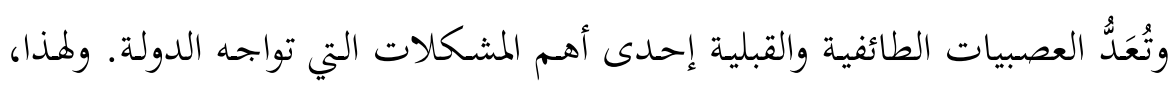

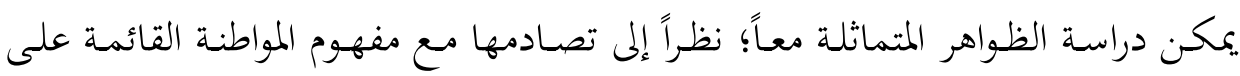

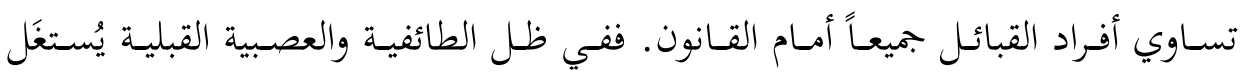

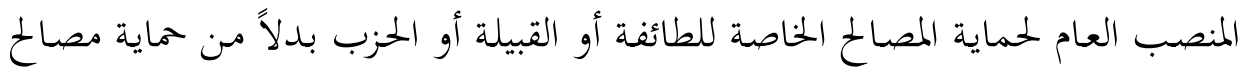

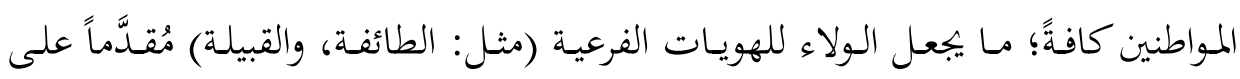

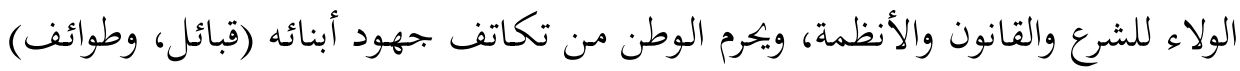
للنهوض به، فتبقى مستويات التنمية في حدودها الدنيا.

\section{خامساً: دولة الرسول}

اتسمت دولة الرسول في المدينة عند بلدء تأسيسها بعدة سمات مهدت السبل لبناء دولة الأمة التي تستوعب التنوع العرقي والملي، ومن هذه السمات:

\section{ا ـ فتحت المجال لتلاقي الشعوب والقبائل في أمة الإسلام:}

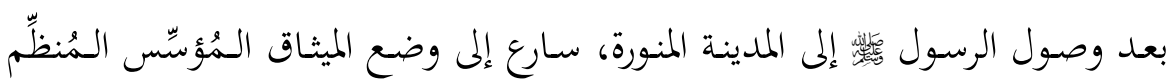

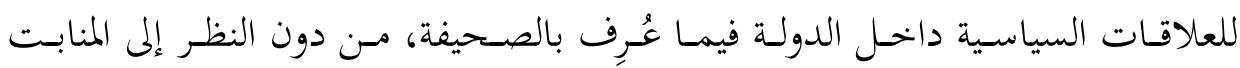

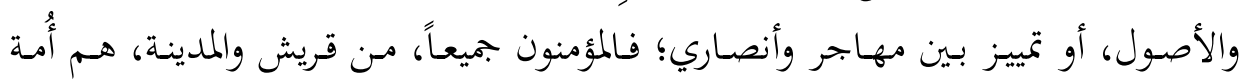

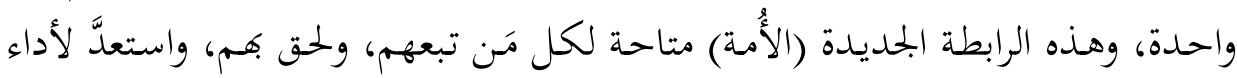

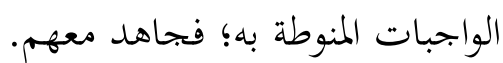

وقد ركَّز إعلان الصحيفة على أهمية ما يسمى اليوم دولة القانون، التي يلتزم جميع

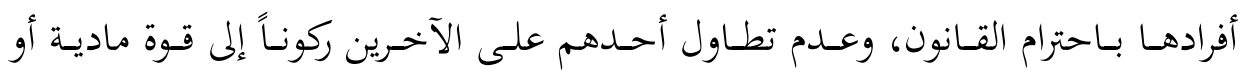


معنويـة. "فـالمؤمنون المتقـون أيسـيهم على كـل مَسن بغى علـيهمه، أو ابتغى دسـيعة ظلـم

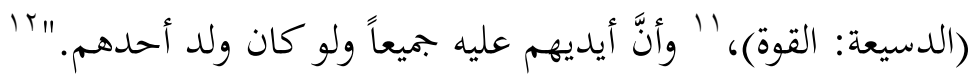

وهـذا الالتزام بالخضـوع لدولة القـانون يُمثّل إحـدى أهـم الـدعائم التي تسـاعد على

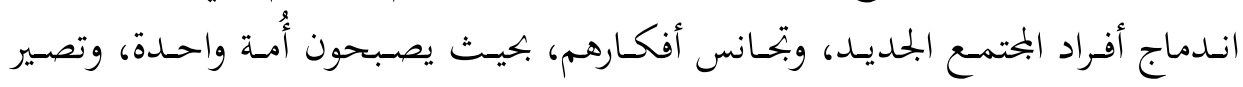

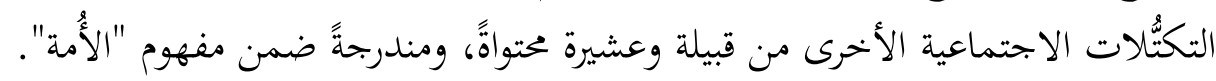
أمَّا عدم رسوخ دولة القانون فيدفع كل فرد إلى الاستقواء بعشيرته وقبيلته لنيل حقه

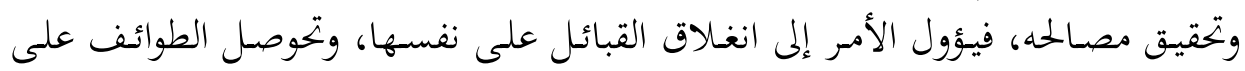
أفرادها؛ ما يُعوِق اندماج الأفراد، وبتحانس أفكارهم ليكونوا أُمة تنصهر في بوتقتها الأعراق

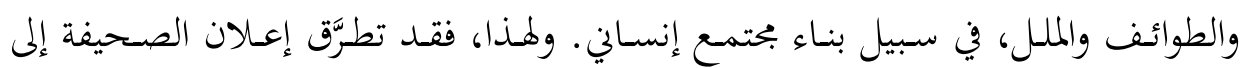

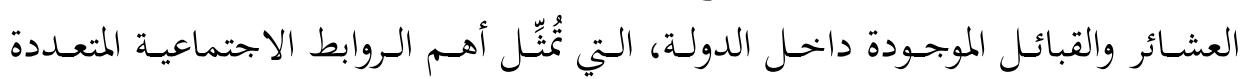

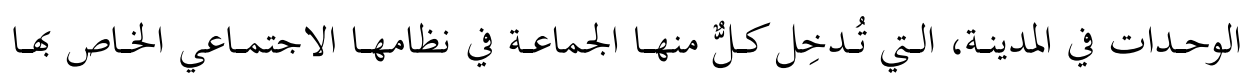

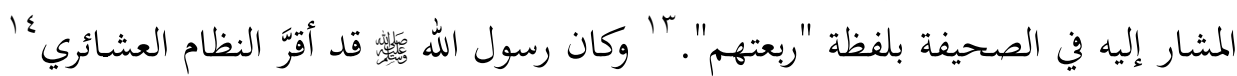
أساساً للاستيطان، والتعاون؛ نظراً إلى تغلغل هذا النظام في النفوس، وما فيه من فئه مصلحة

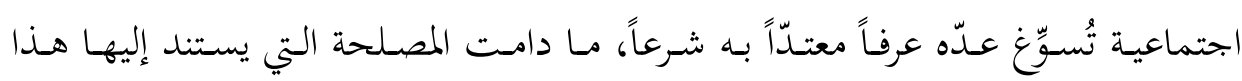
العرف لا تتنافن مع المصالح المعتبرة في الشريعة؛ فقد نَصَّ إعلان الصحيفة على على أنَّ أفراد العشائر يتعاقلون معاقلهم، ويفْدون عانيهم بالمعروف والقسط بين المؤمنين.

\section{r. العشيرة بوصفها تكتُّلاً اجتماعياً لا تكتلاً سياسياً:}

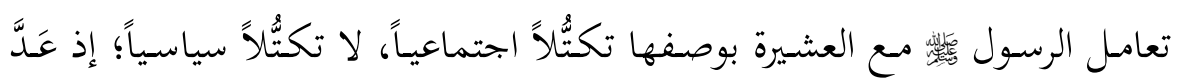

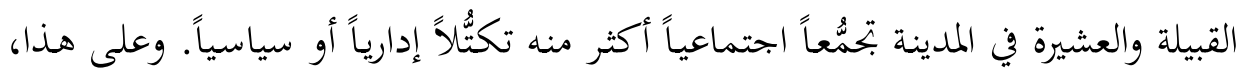

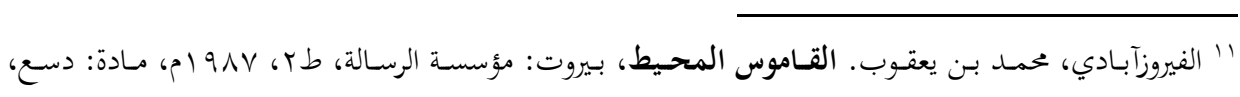
ص ص 9 ص 9 (i) r' انظر نص الوثيقة: حميد الله، محمد. مجموعـة الوثائق النبويـة للعهـد النبوي والخلافـة الراشـدة، بيروت: دار

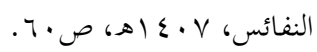

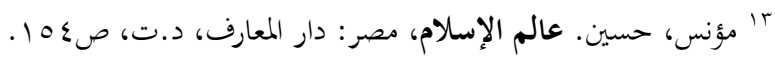

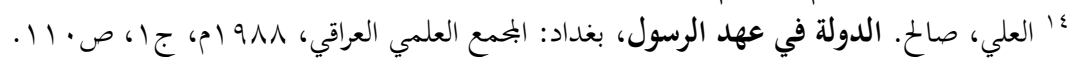

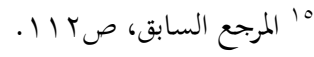




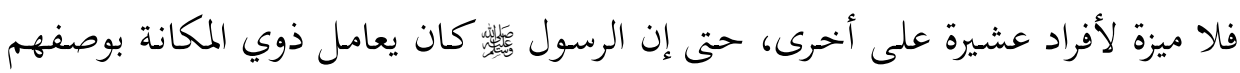

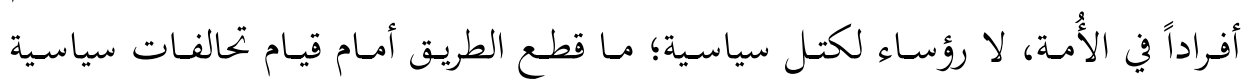

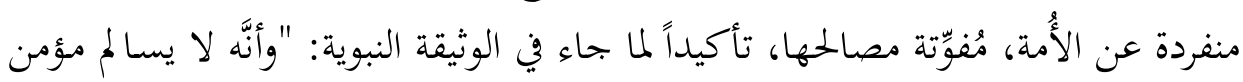

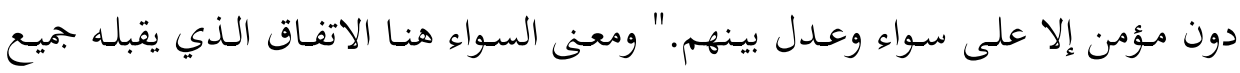

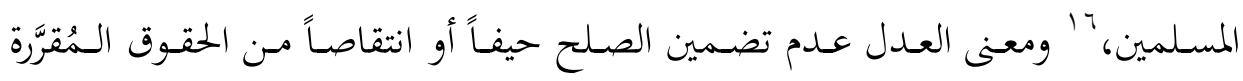

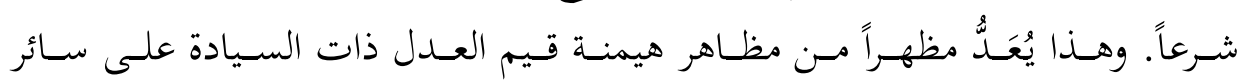

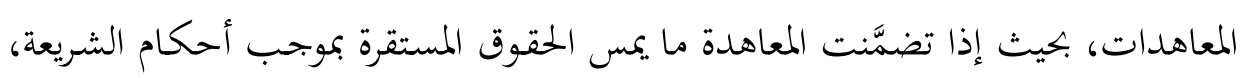

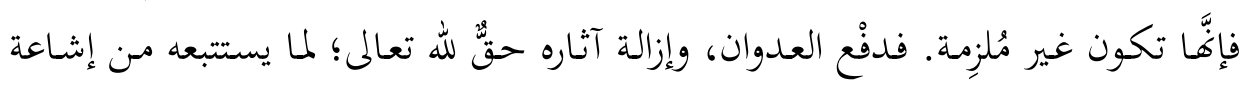

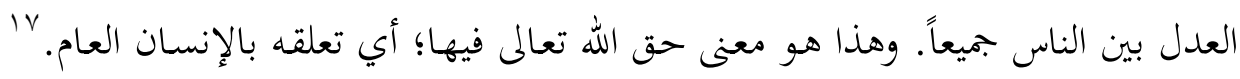

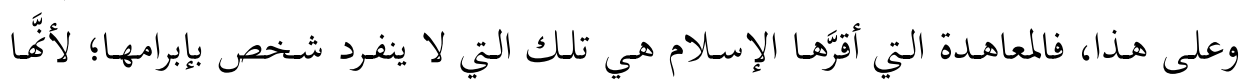

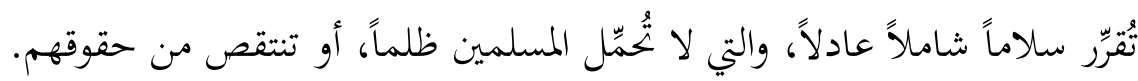

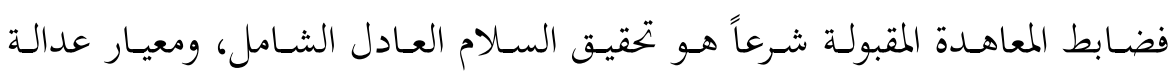

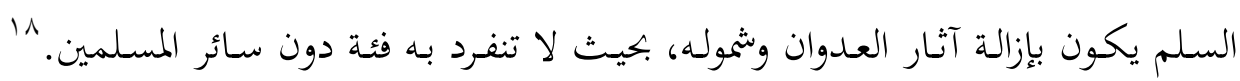

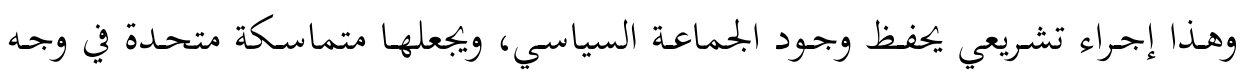
الآخرين.

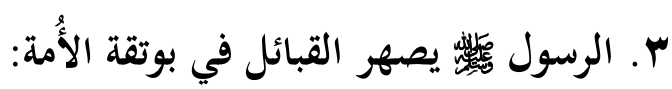

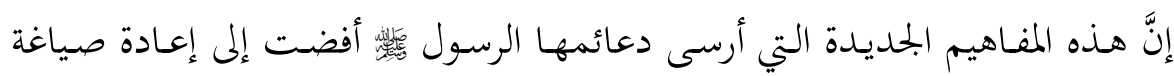

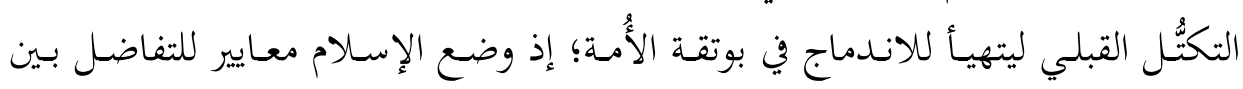

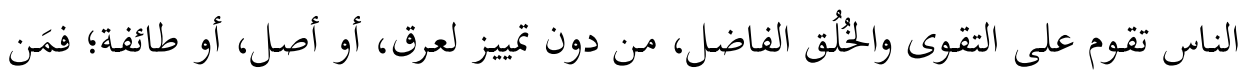

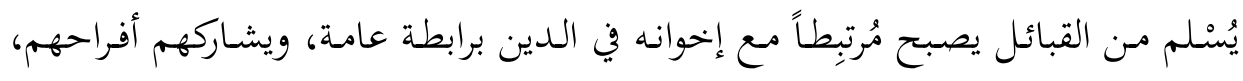

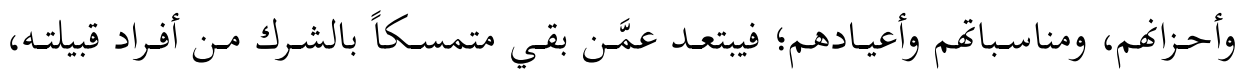
ويندمج في الرابطة الجديدة (الأُمة المسلمة).

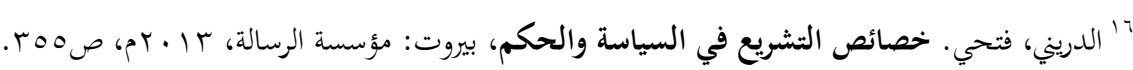

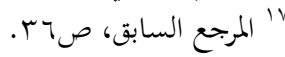

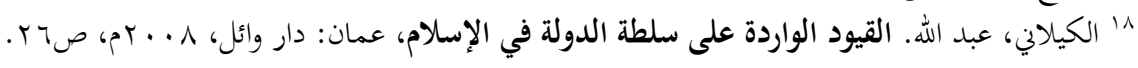




\section{سادساً: الطائفية وتناقضها مع أسس العمران الخلدوني}

بـيَّن ابـن خلـدون أنَّ أسـباب وجـود الجماعـة يتمثَّل في حفـظ مقومــات وجودهـا

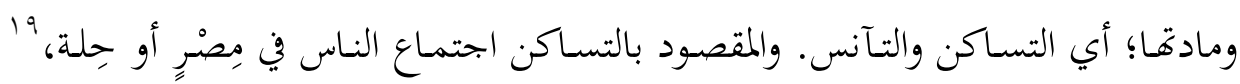

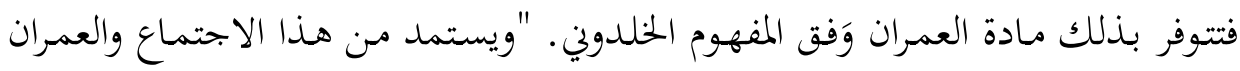

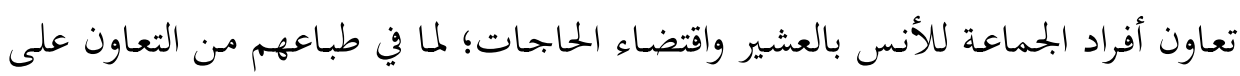
المعاش."r.

وبقـاء التسـاكن واستمراره يقتضـي وجـود سـلطة سياسـية تـدفع التخاصـم، وتُقُقِق

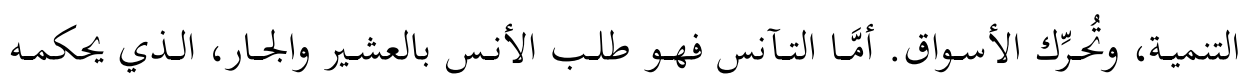

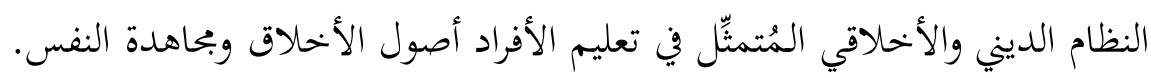
وأمَّا ما ذكره ابن خلدون من حاجة العمران إلى تساكن أفراده (أي اجتماعهم)؛

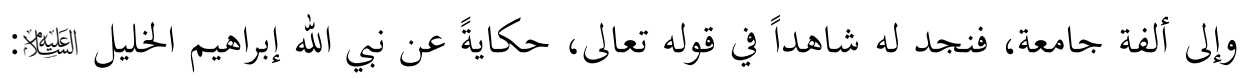

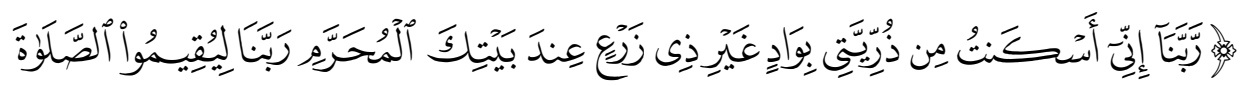

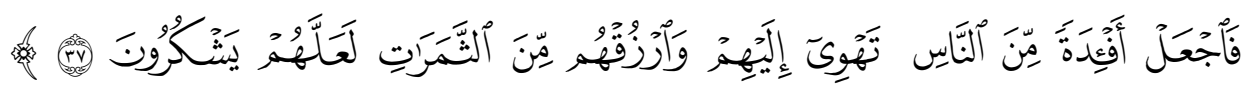
(إبراهيم:Vr). فالاجتماع يتطلَّب توفر الألفة الجحامعة والرزق لتلبية الحاجات الإنسانية. وقد نبَّه القرآن الكريم على الخلل الذي يصيب صميم الأنظمة السياسية حين تُدمَّر الألفة الجامعة، وعرض لذلك مثالاً على فرعون الذي جعل أهلها شيعاً متقاتلين، فأخلّ الّل

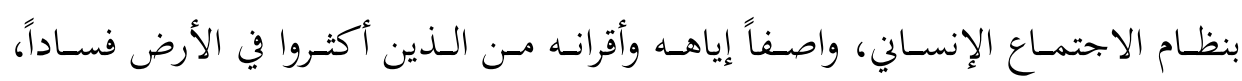

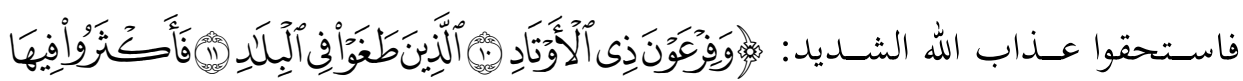

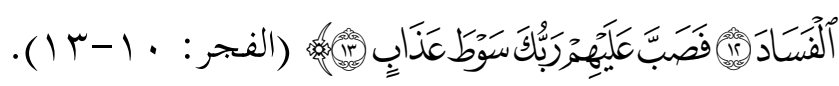

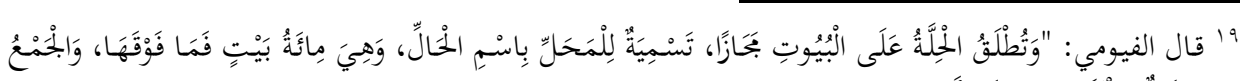

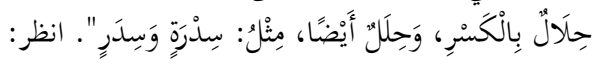

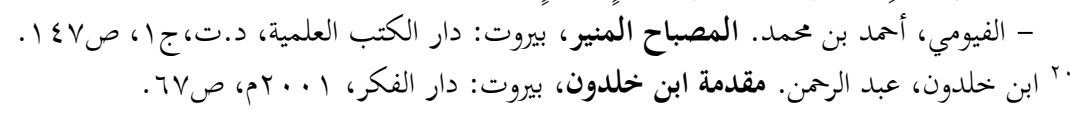


سابعاً: كيف يمكن بناء فكر المواطنة في دولة إسلامية تقوم على أساس ديني؟

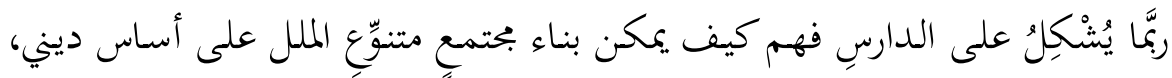

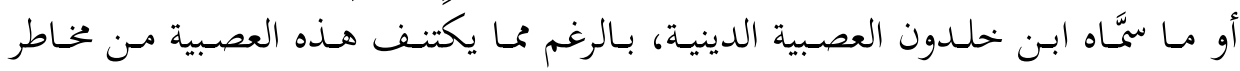

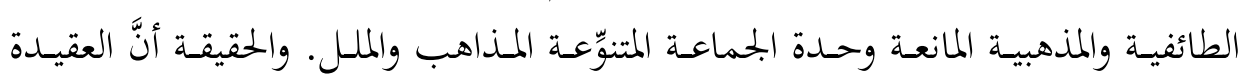

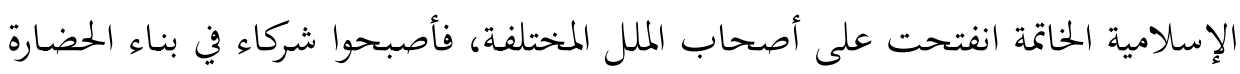

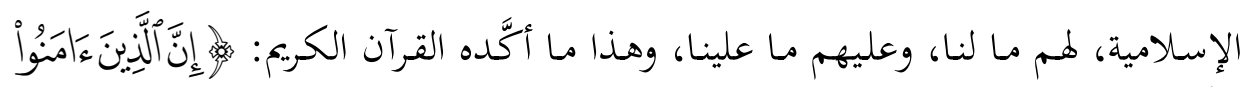

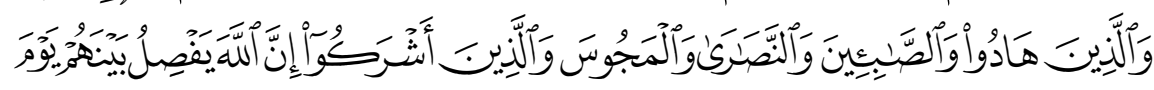

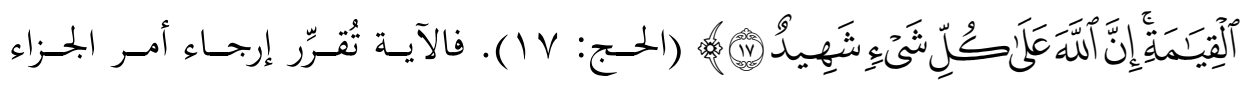

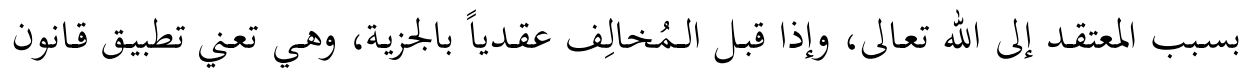

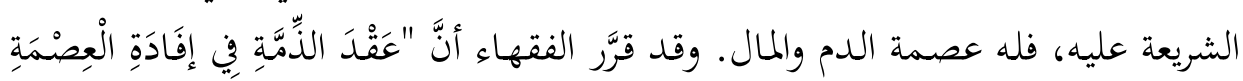

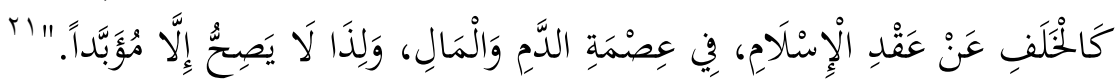

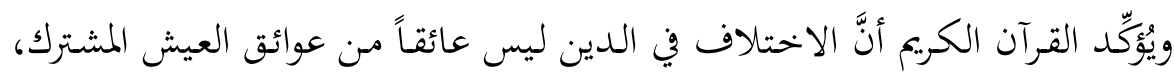

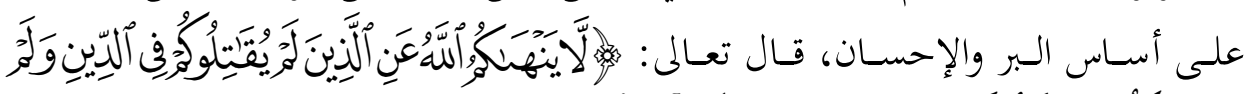

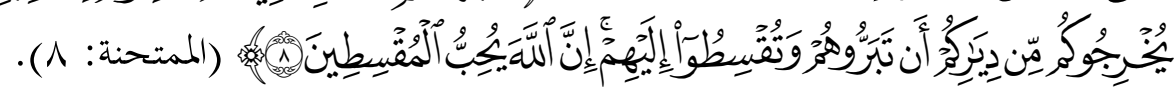

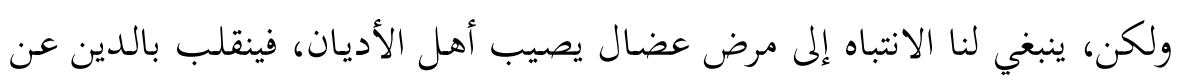

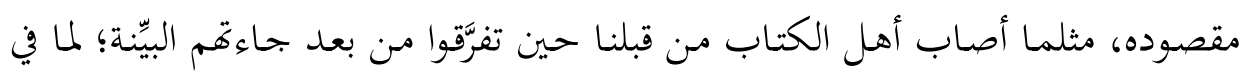

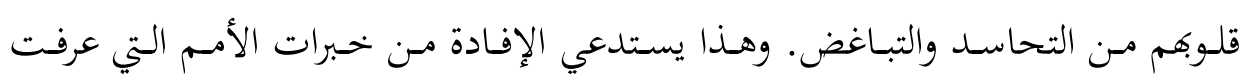

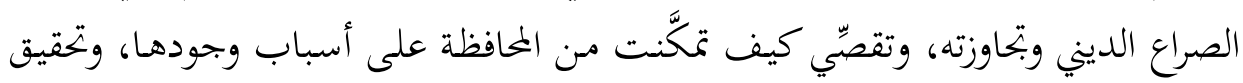
فضنها.

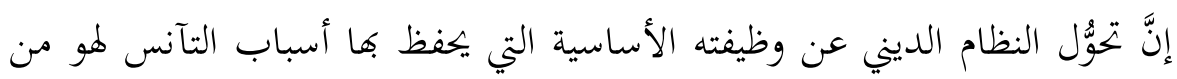

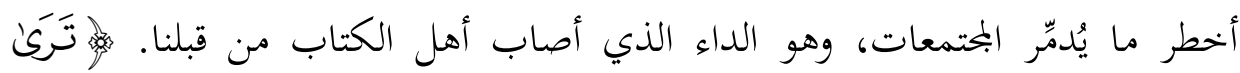

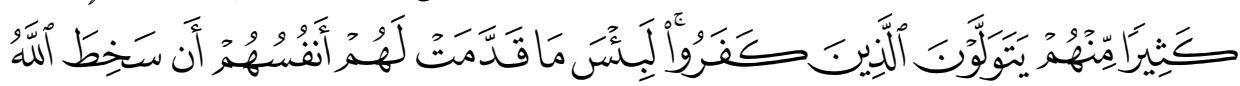

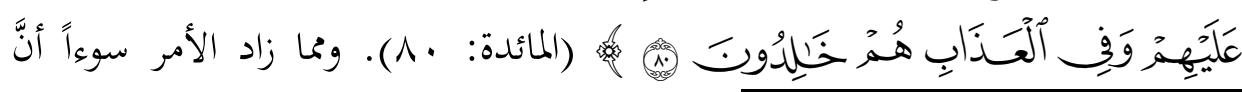

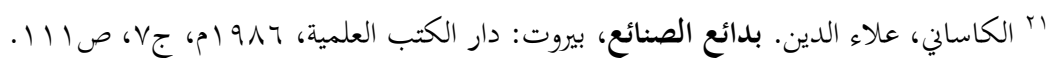




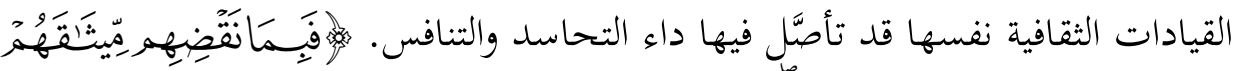

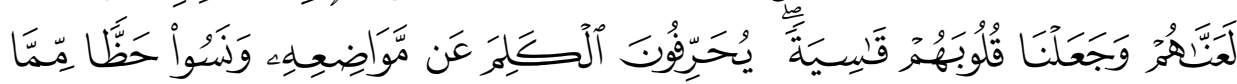

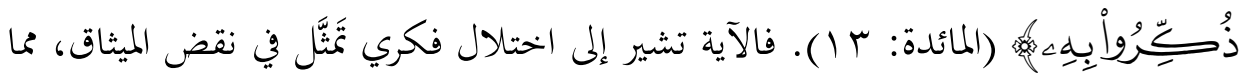

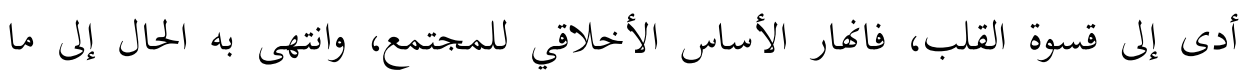

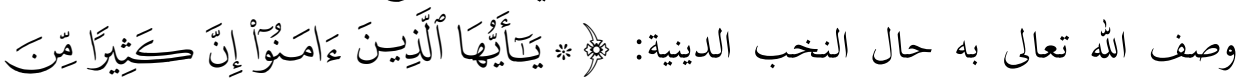

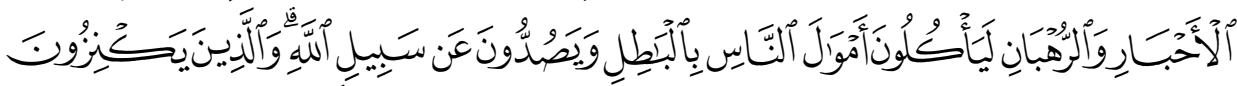

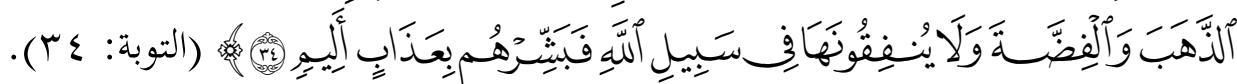
وكان فساد الذمم الذي أصاب النخب الثقافية موجباً لحلول سُنن الله تعالى فيهم؛ بزوال

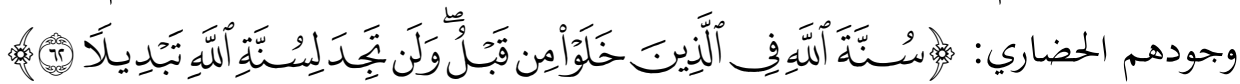

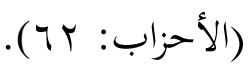

ولا شـكَّ في أنَّ حـديث القرآن الكريم عن الأمـراض التي أصـابت أهـل الكتـاب مـن قبلنا هو دعوة للاعتبار والوقاية؛ فما أصابهم قد يصيبنا، والماضي أشبه بالآتي مـ الماء بالماء.

\section{ثامناً: موقف الجويني من أهل البدع والطوائف المتمردة على الدولة} يُمثِّل الجـويني المدرسـة التي سعت إلى وضـع حلـول عمليـة لمواجهـة مكامن الخطـر

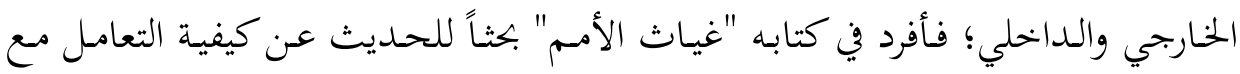

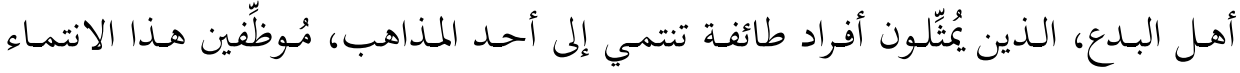

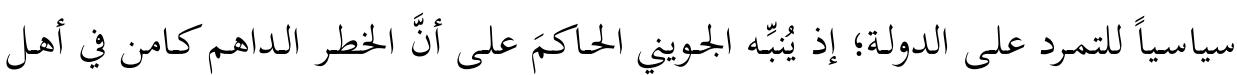

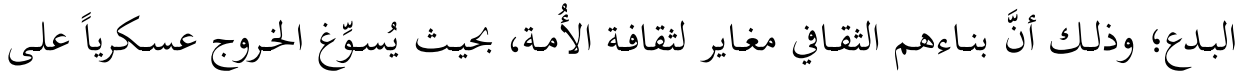

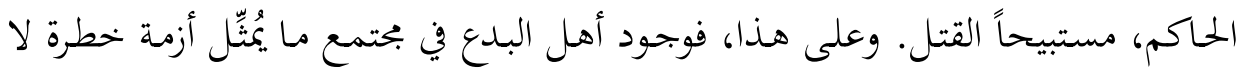

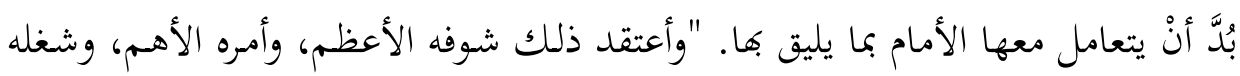

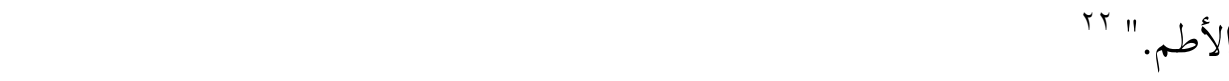
rr الجويني، أبو المعالي عبد الملك. غياث الأمم، تحقيق: عبد العظيم الديب، قطر: مكتبة إمام الحرمين، ا لع ام، 
وينبغي أنْ يُفَهَم كلام الجويني هذا بناءً على خبرته التاريخية؛ فقد عاث في زمنِ فتندة

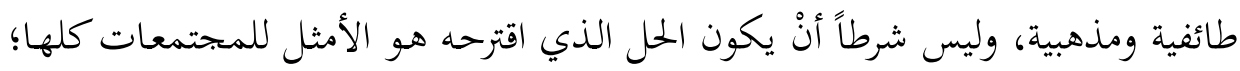

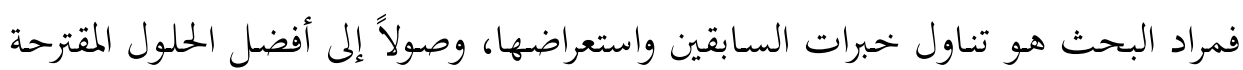
وأبحعها.

ومشكلة أهل البدع التي يتحدث عنها الجويني تتمثَّل في التكفيرين الذين قد يظهرون

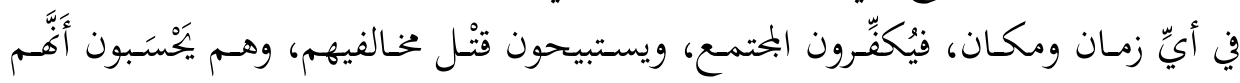

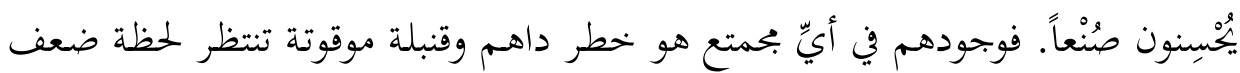

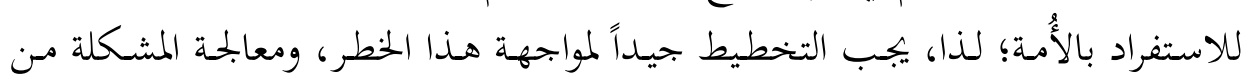

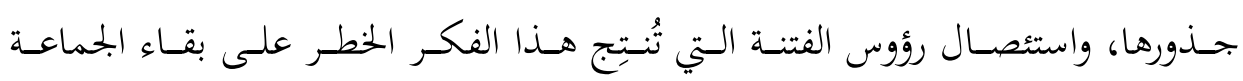
ووجودها.

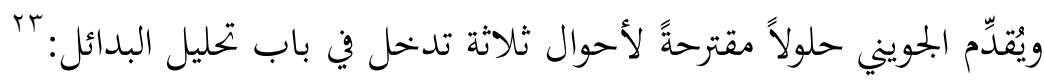

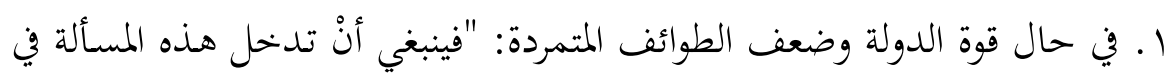

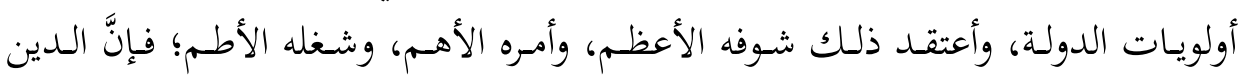

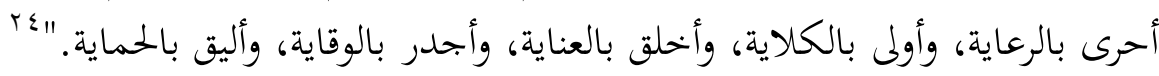

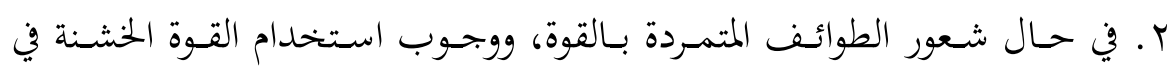

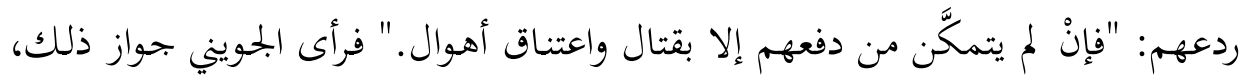

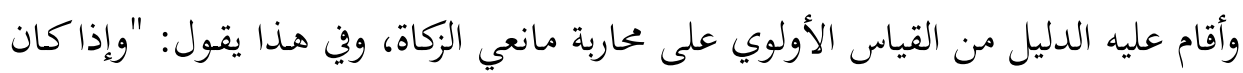

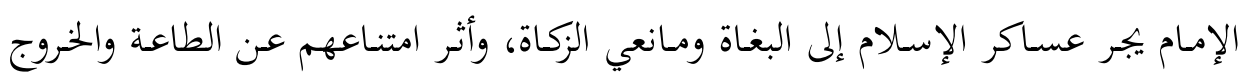

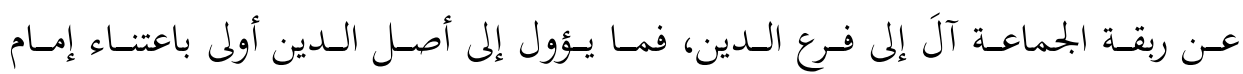

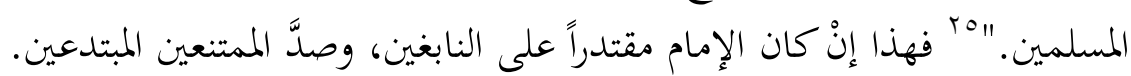
r. في حال تفوق الطوائف المتمردة على الأمام عسكرياً: "وإنْ تفاقم الأمر، وفات

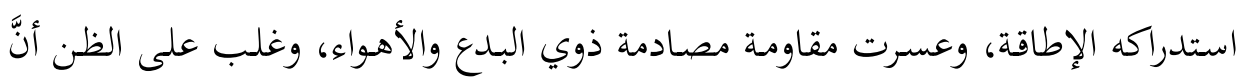

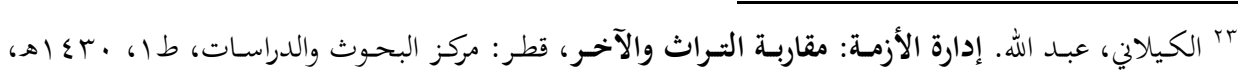

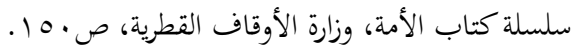

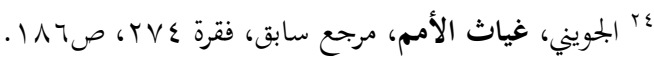

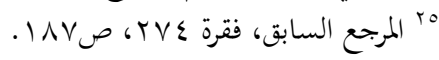


مسـالمتهم ومتـاركتهم وتقريـرهم على مـذاهبهم وجـه الـرأي، ولـو جـارهم لتـألبوا وتأشسبوا

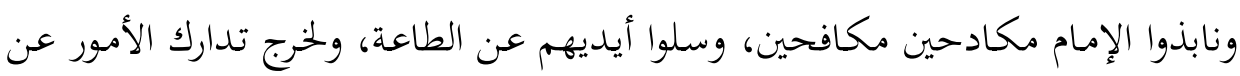

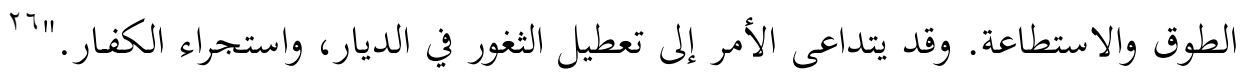
وهنا يقترح الجويني التعامل مع الأزمة على النحو الآتي:

أ. عـدم استخدام القوة الخشنة؛ "حتى لا يظهر مـا يخرق حجـاب الهيبة، فيتجرأون

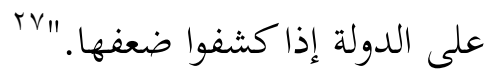

ب. استخدام حرب العقول والإرادات والحرب المعلوماتية؛ إذ يقول: "والمرء يعجر لا

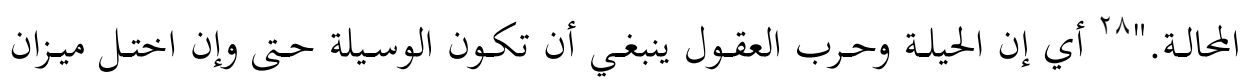
القوى.

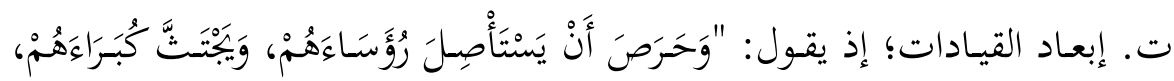

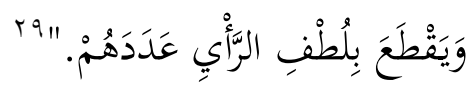

ث. تحسيُّن الوقت المناسـب للتـدخل، "فبإنْ كان كذلك لمُ يظهر مـا يخـرق حجـاب

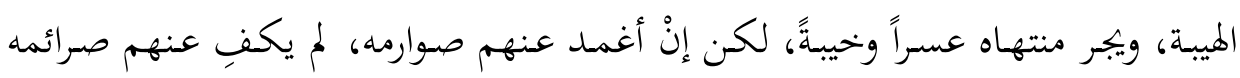

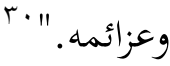

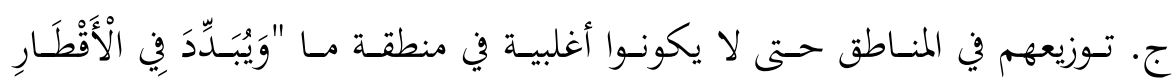

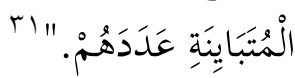

ح. ويجمع النقاط السابقة مفهوم استخدام الحيلة بوجود فرصة سانحة للخروج مـن فئن

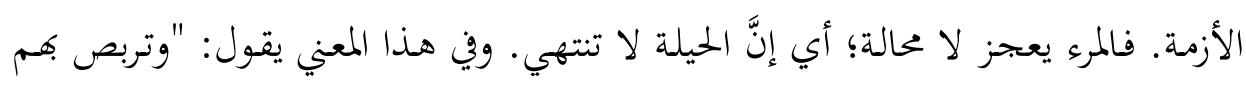

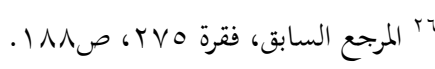

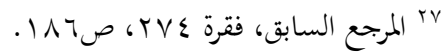

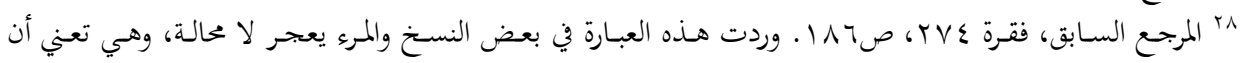

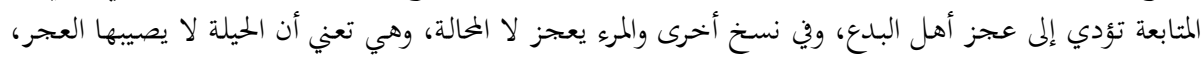

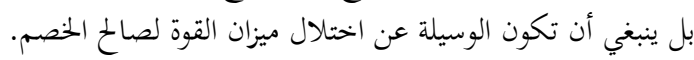

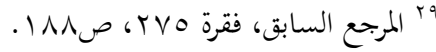

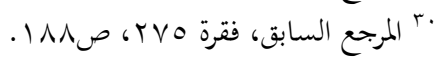

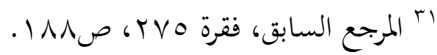




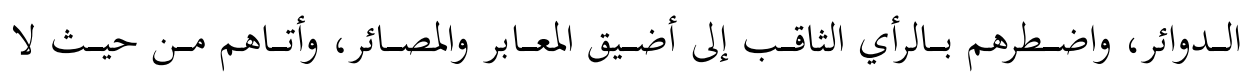

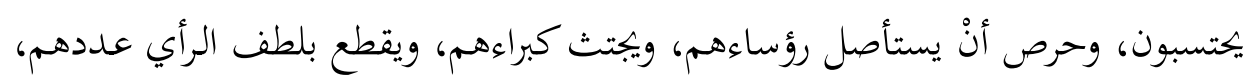

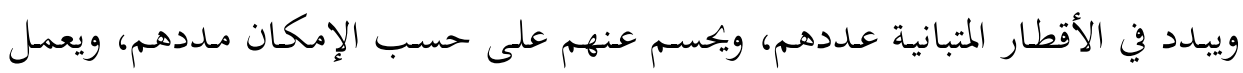

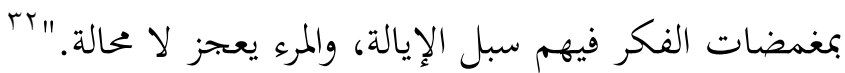

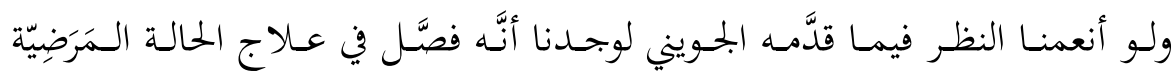

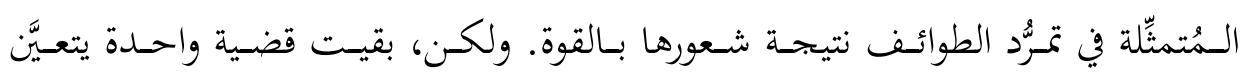

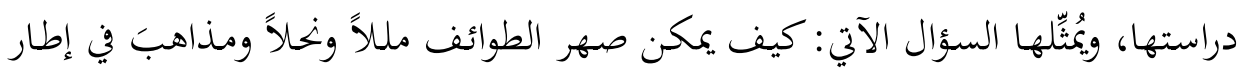

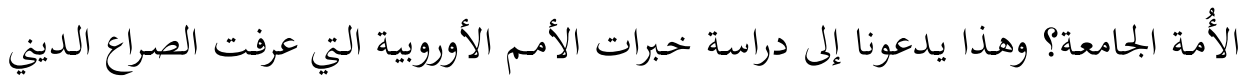

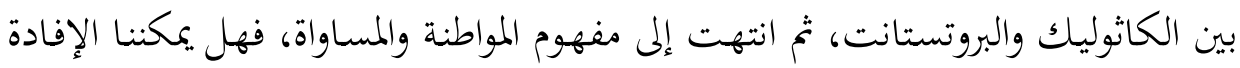

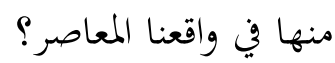

\section{تاسعاً: التأسيس لمفهوم المواطنة: تجربة الأمم الأوروبية أنموذجاً}

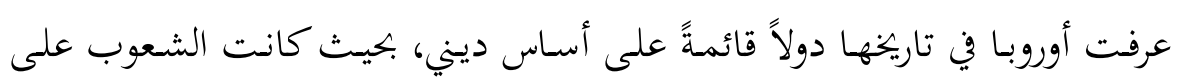

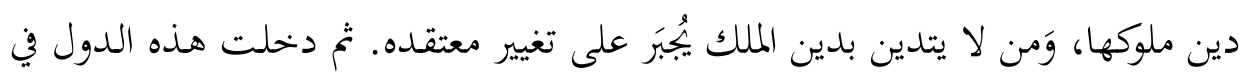

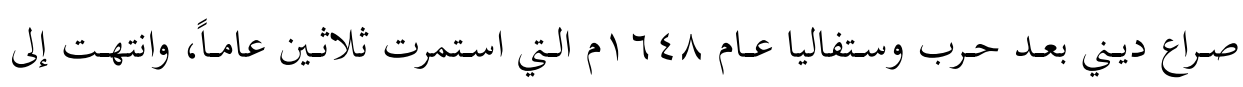
فكرة الاعتراف بالدولة القومية ذات السيادة؛ لإبعاد سلطة الكنيسة الكاثوليكية، ومنع

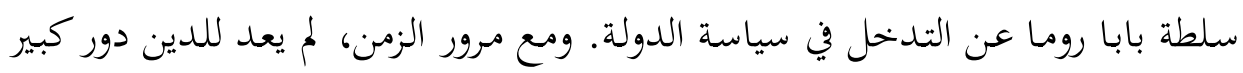

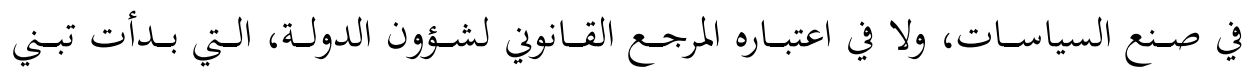

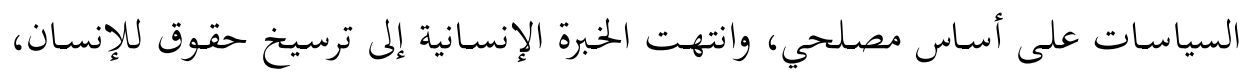

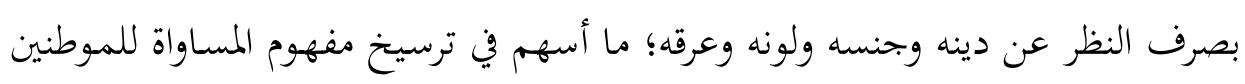

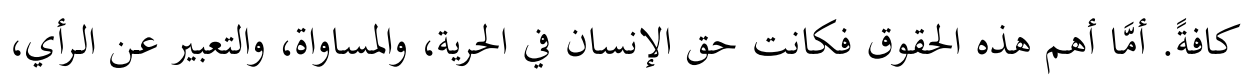

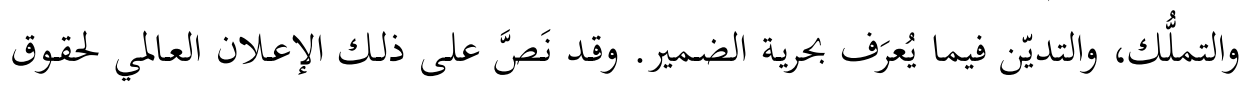

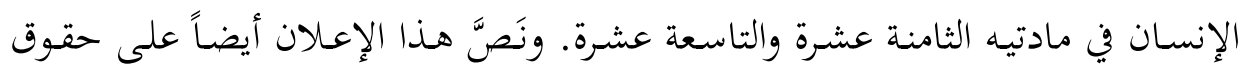


سياسية للمواطن تتضمَّن حقه في الانتخاب، والمشاركة في حكم بلاده. وقد تأكَّد ذلك

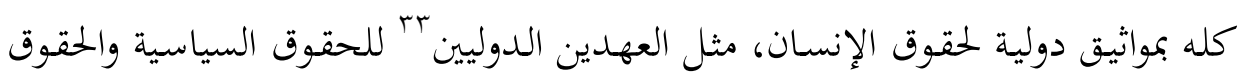

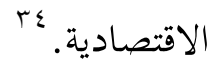

وتُعَدُّ التجربة الأوروبية أنموذجاً لافتاً للكثير مـن المفكرين والسياسيين العرب، وهي بلا ريب تستحق التوقّف عندها، ودراستها، والإفادة مـن خبرقا في تجاوز أسباب الصراع

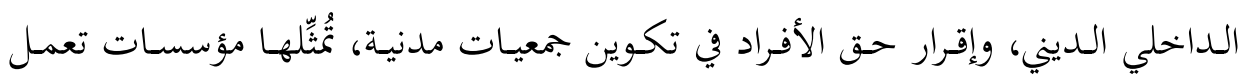

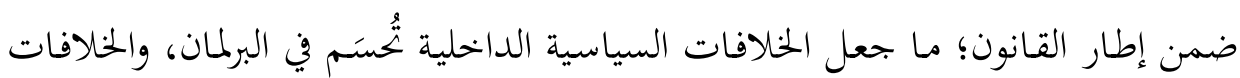
الدولية تُحسَم في المؤسسات الدولية.

فكل ذلك يجب الإفادة منه، ولكن ببصيرة ثاقبة، ورؤية مستنيرة؛ وذلك أنَّ كثيراً مـن

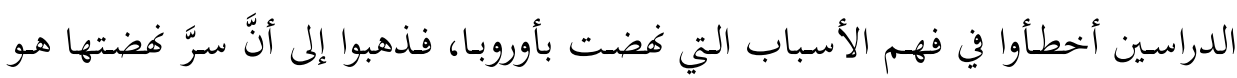

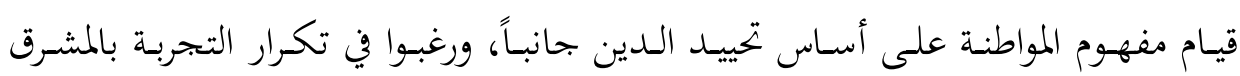

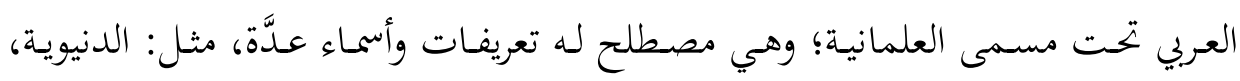
وإلغاء الإيمان بالآخرة. وهذا ما ترفضه المعايير والضوابط الإسلامية. وهناك مَن ينظر إلى لى

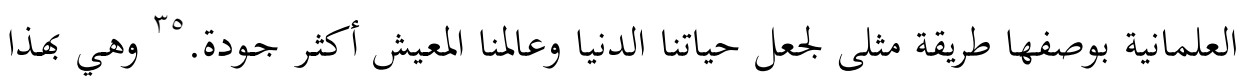

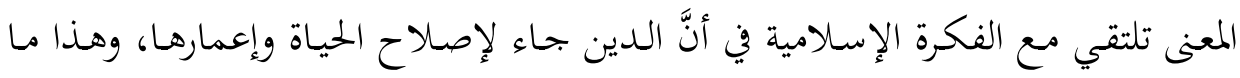

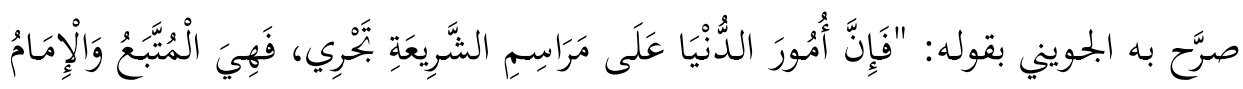

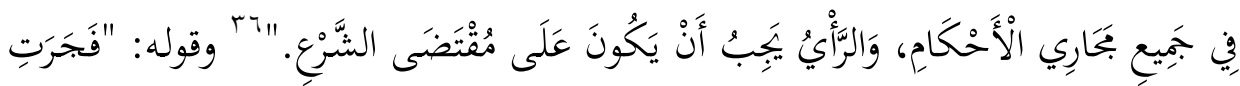

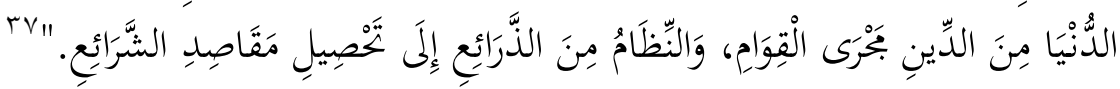

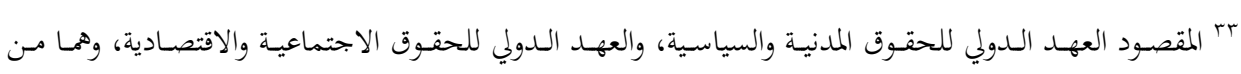
الاتفاقيات الدولية لحقوق الإنسان.

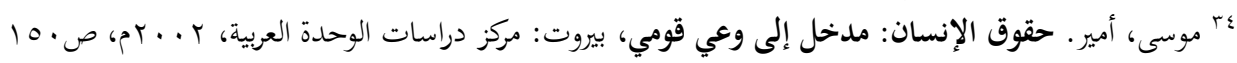
وما بعدها.

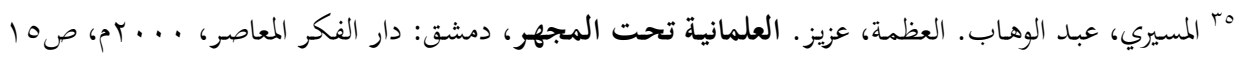
وما بعدها.

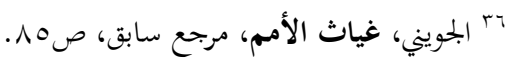

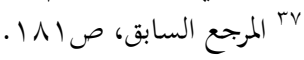


لكنَّ الفكر العلماني بهذا المعنى القريب من الشريعة لا يملك في داخله معالجة لرغبة الإنسان الجامحة في السيطرة على الشهوات؛ فهي لا تتحصَّل إلا بالإيمان بوجود الآخرة.

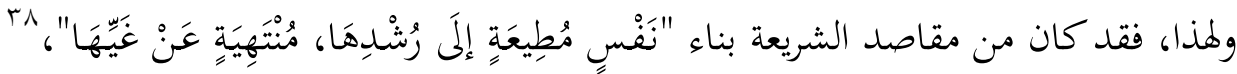

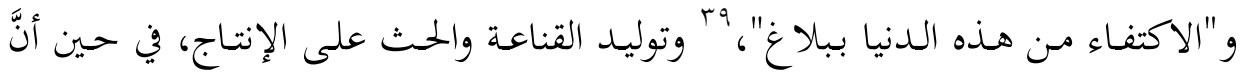

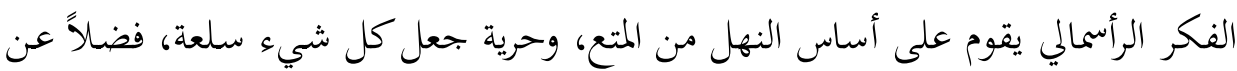

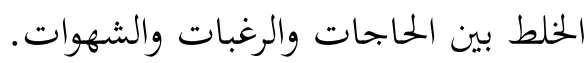

والحقيقة أنَّهَ لا يمكن السيطرة على هذه الرغبات إلا ببناء قيمي يعظم الإنتاج على

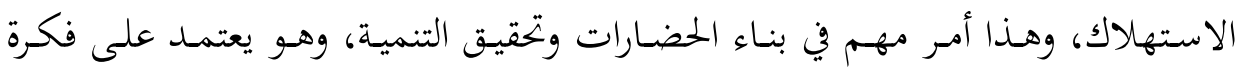

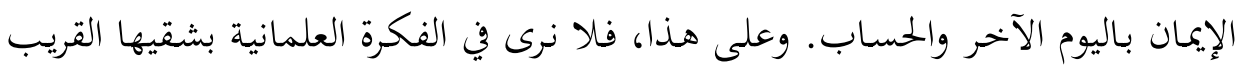

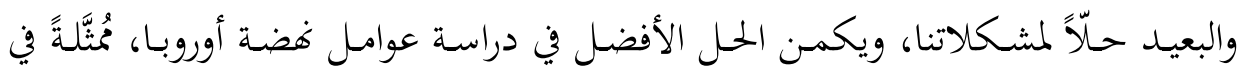

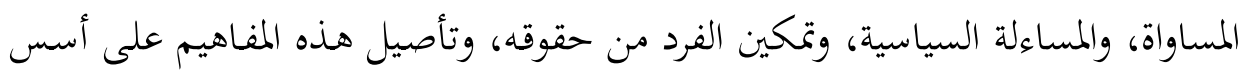

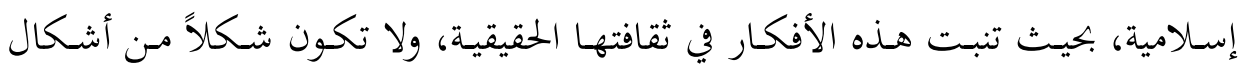
الهيمنة الغربية.

عاشـراً: التحـديات التي تواجـه مُكوّنـات المجتمـع الحـديث، وسبل بنـاء الجماعـة الواحدة

تتنوع الهويـات الدينيـة والطائفيـة والمذهبيـة والقوميـة والجهويـة في الكثير مـن البلاد

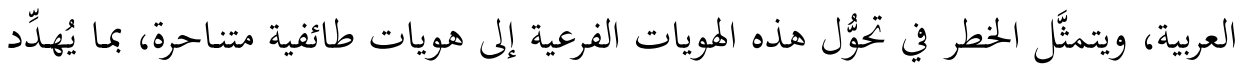

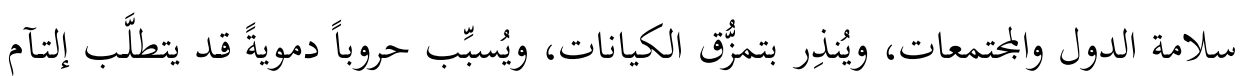
جراحها سنين طويلة.

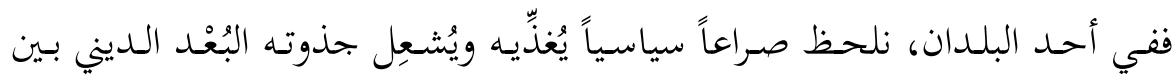

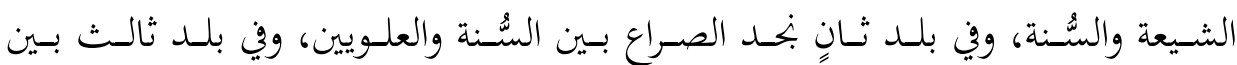

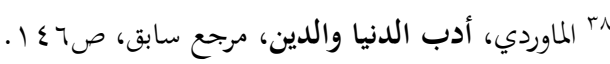

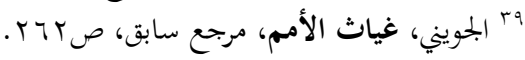




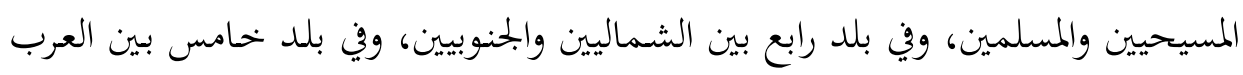

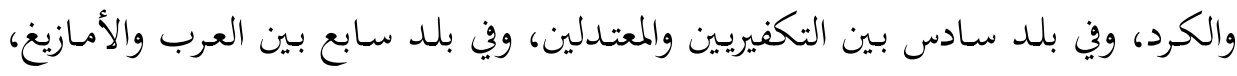

والملاحظظ أنَّ هـذه الحـروب تغفـل التـاريخ الطويلل مـن العيش المشترك، وتستحضـر

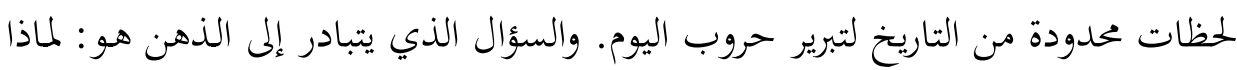

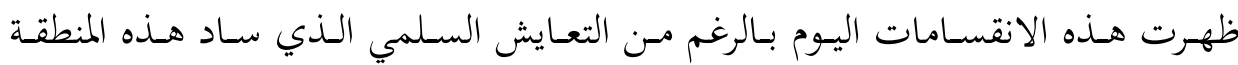

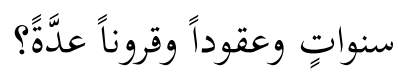

وبخيب عن السؤال بوجود أربعة أسباب أفضت إلى نشوب الصراع اليوم:

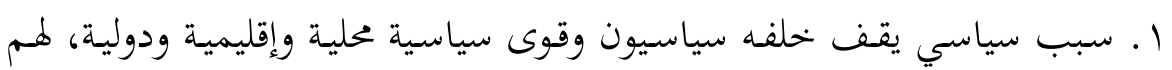

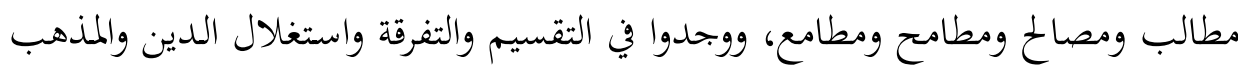

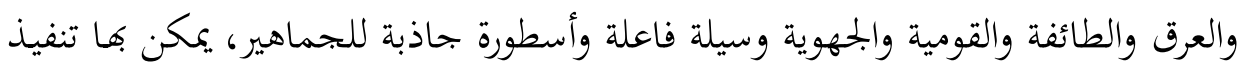

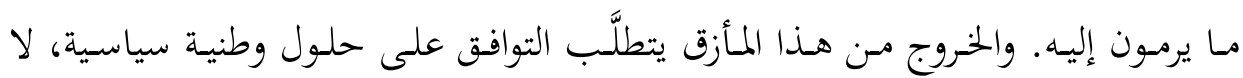

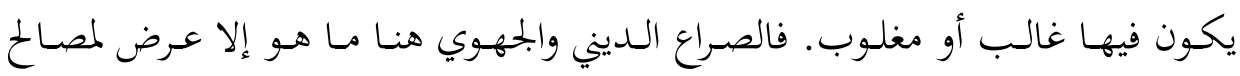

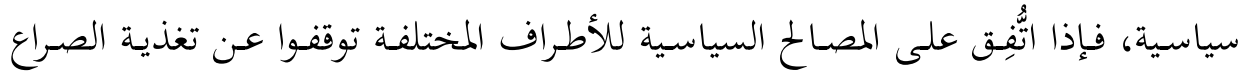
بالهويات الفرعية.

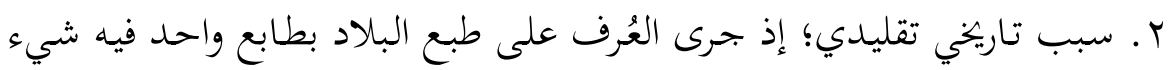

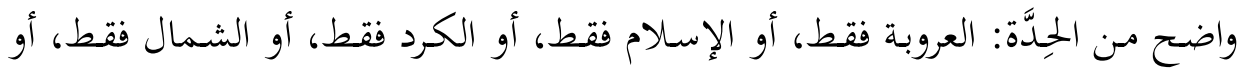

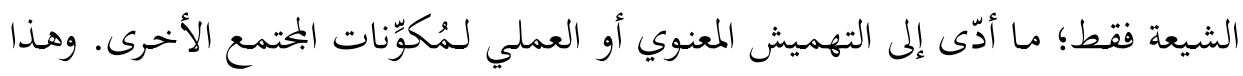

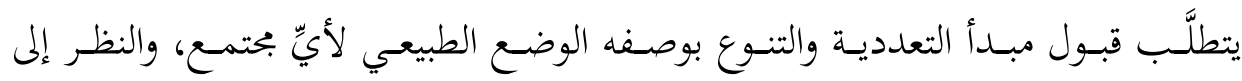

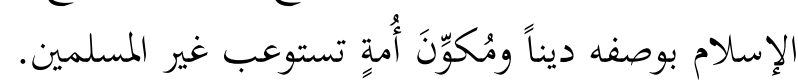

r. سبب سلطة الأنظمة والحكمى؛ فقد دأبت أنظمة الحكمى في كثير مـ الأقطار

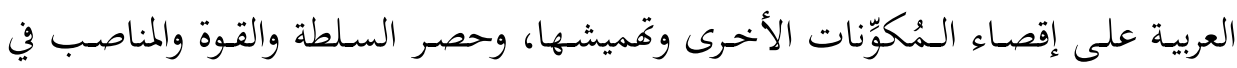

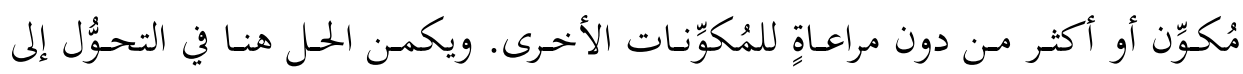

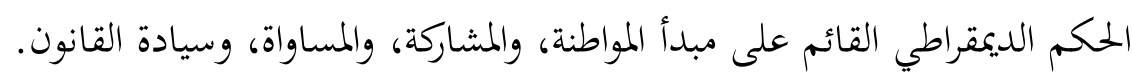


ع . سبب تربوي ثقافي ديني؛ إذ لا تتناول مناهج التربية والتعليم ومنتجات الثقافة

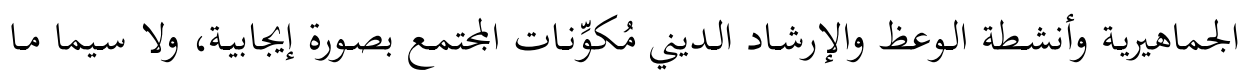
يتعلق بالأديان والمذاهب والطوائف.

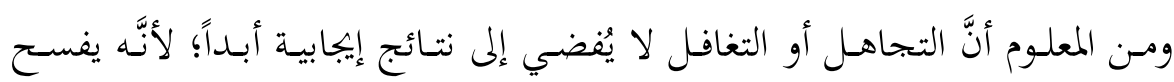

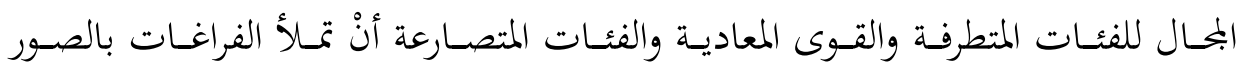

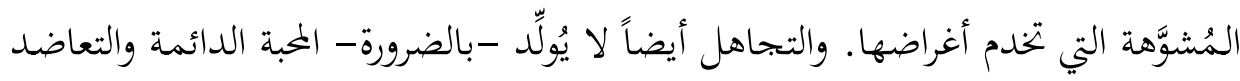

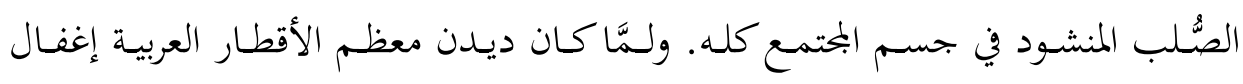

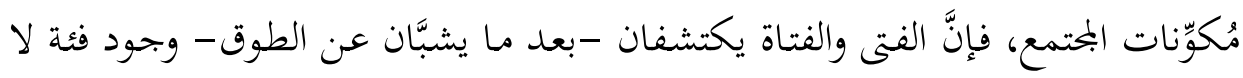

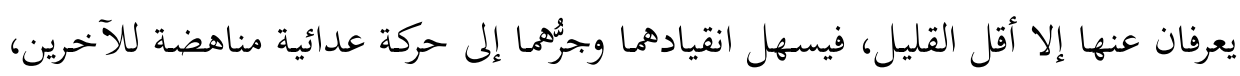

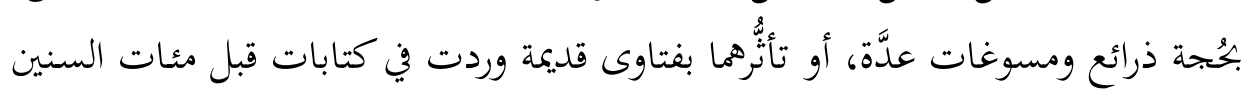

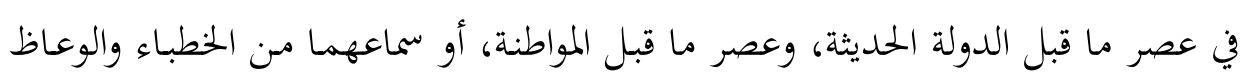

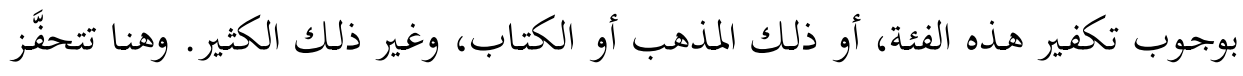

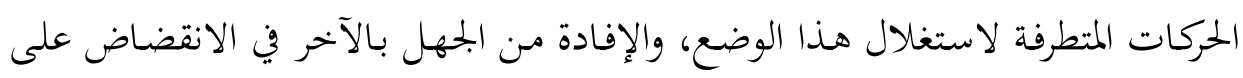

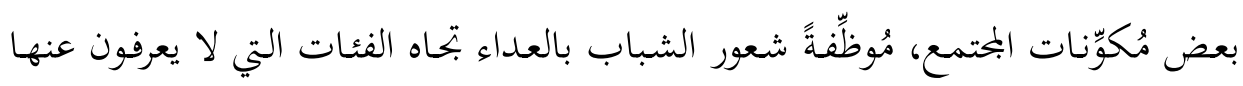

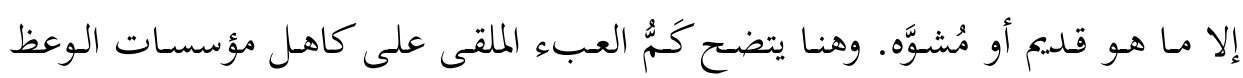
والإرشاد والتربية والتعليم ووسائل الإعلام لتغيير هذه الصورة. تئنح.

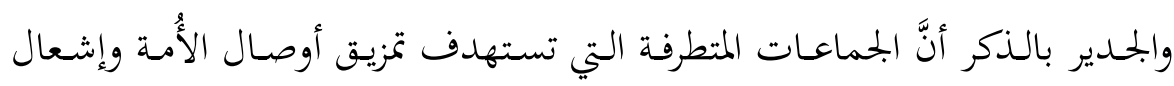

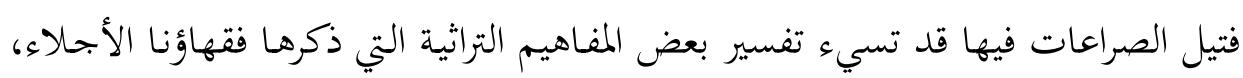

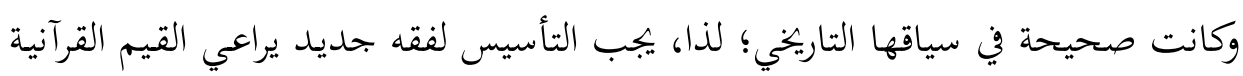

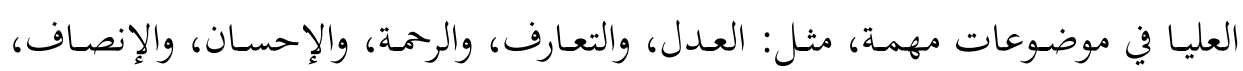

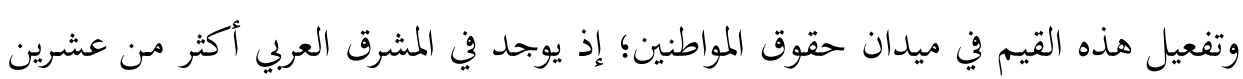

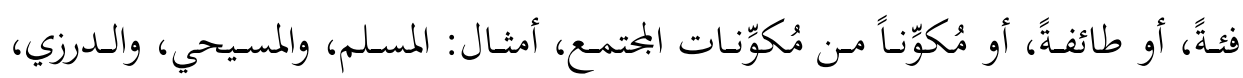

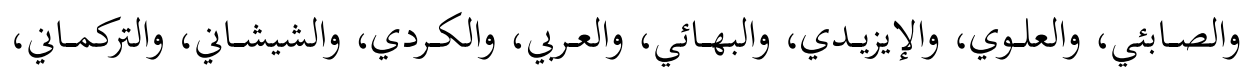

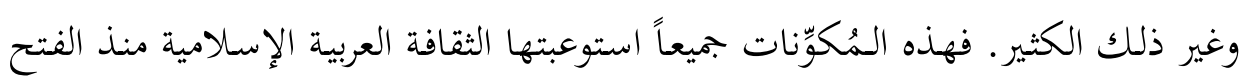




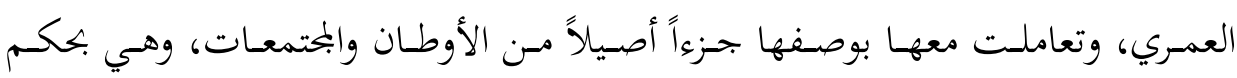

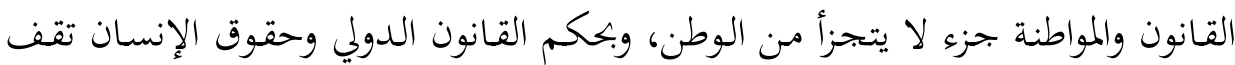
على قدم المساواة في الحقوق والواجبات.

ولكن، مـا الصورة التي يحملها الشباب في أذهاهم عن هذا الموضوع؟ مـاذا يقرأون

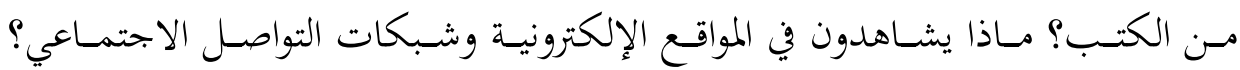

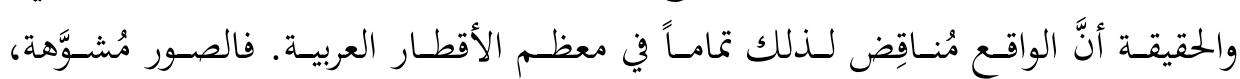

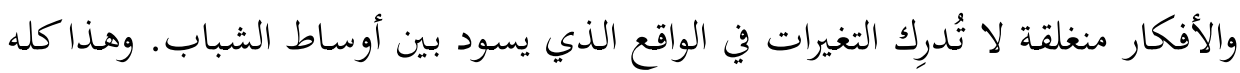

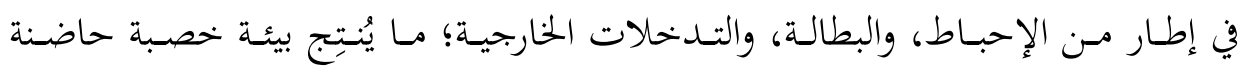

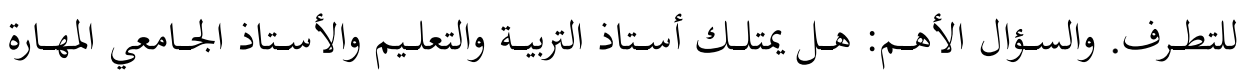

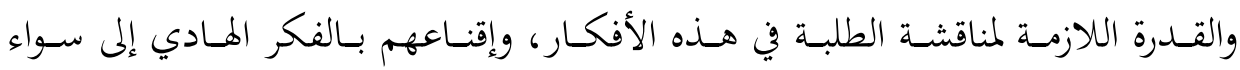
السبيل؟

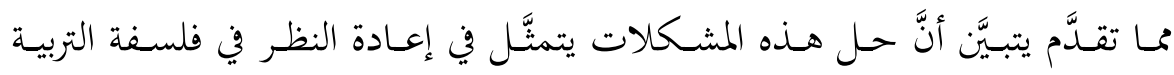

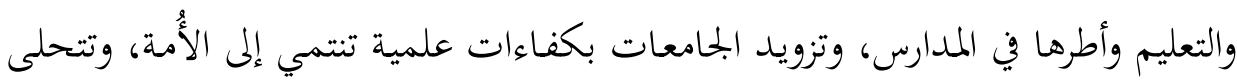

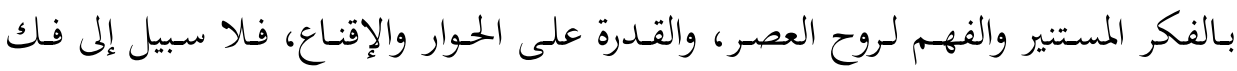

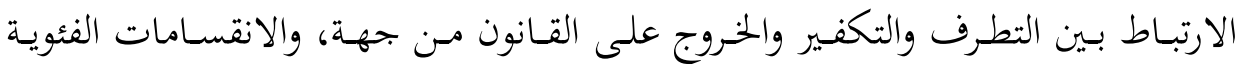

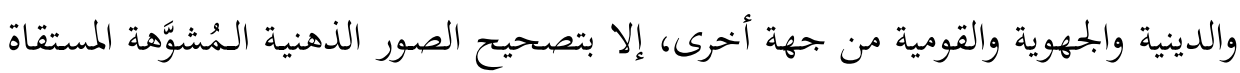

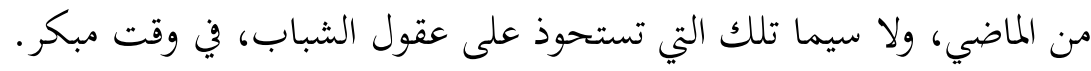

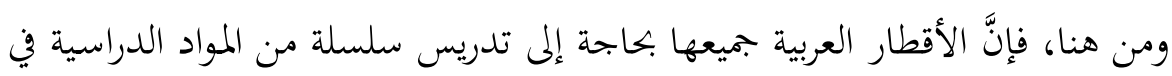

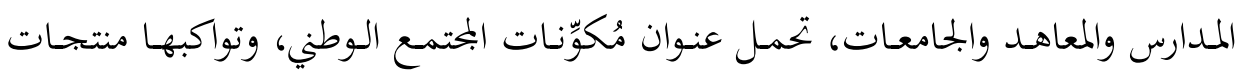

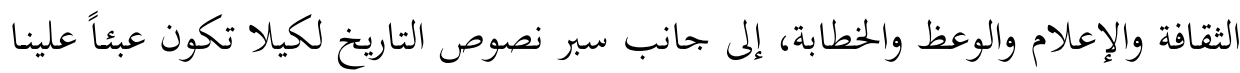

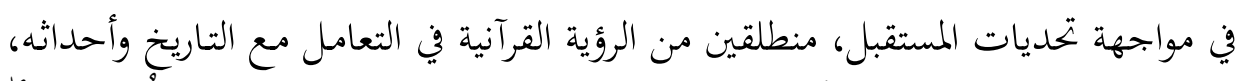

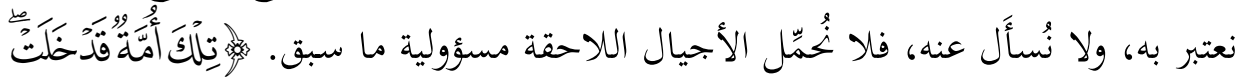

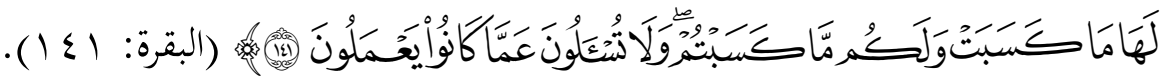




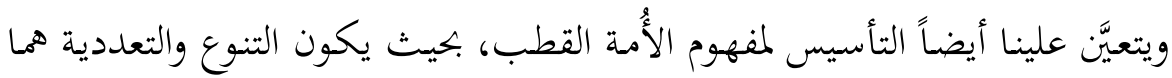

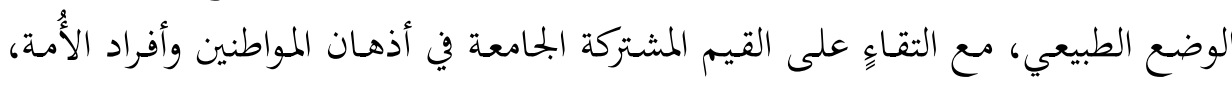

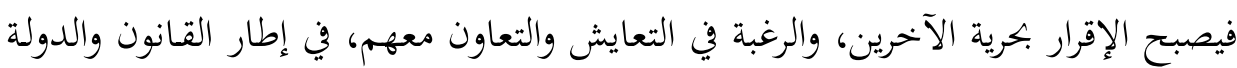

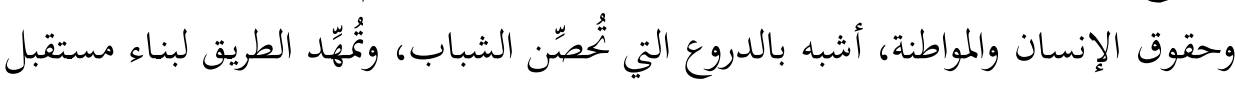

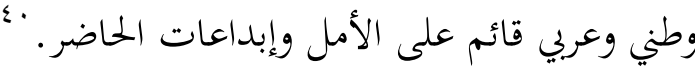

\section{خاتمة:}

تناولت هذه الدراسة التمييز بين الطائفة والطائفية، وبيّنت أن الطائفة تطلق على

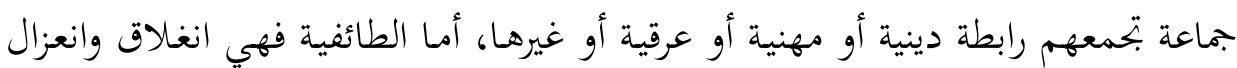

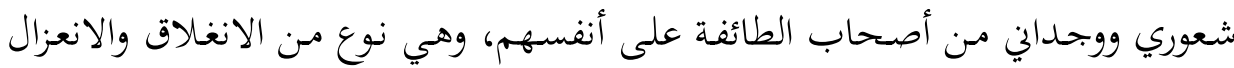

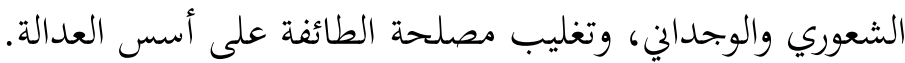

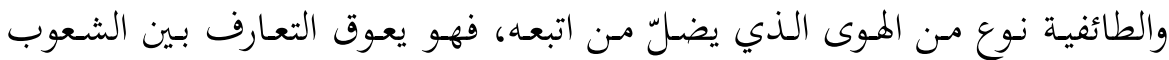

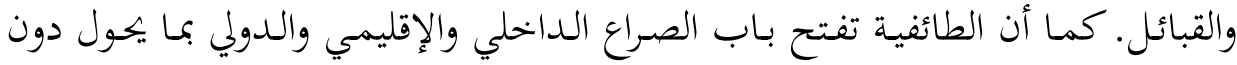

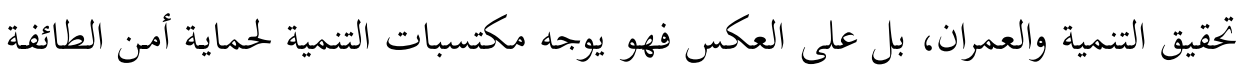

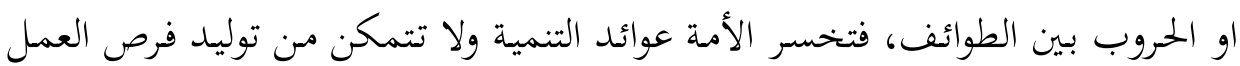
وتحقيق رفاه الأفراد.

والعوامل التي تؤدي إلى نشوء الطائفية خليط من العوامل السياسية والدينية ودافع

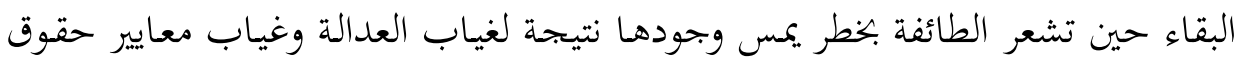

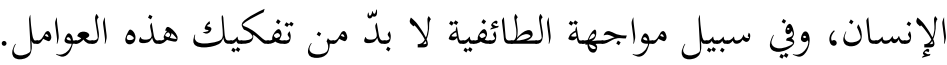

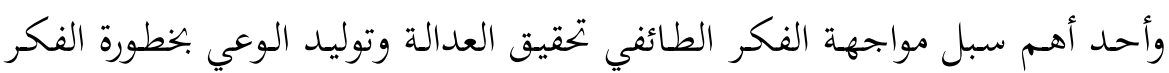

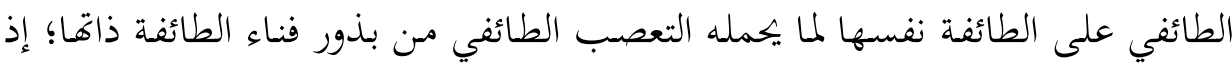

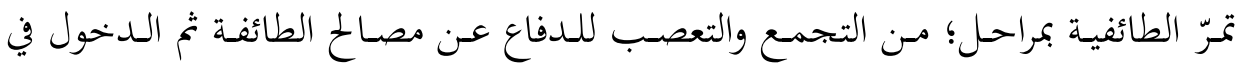
• بدران، إبراهيم. مكونات المجتمع وتصحيح الصورة المشوهة، الموقع الإلكتووني لطلبة نيوز: - http://www.talabanews.net/ar. 
صراع مع الطوائف الأخرى، وهنا ينفتح الباب للتدخل الخارجي والدولي ولتصبح البلاد

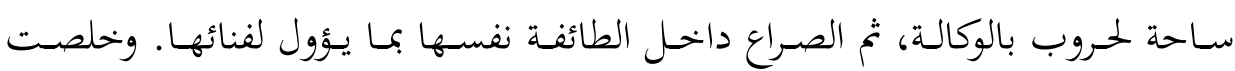

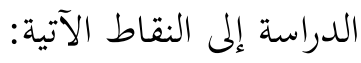

ا ـ إن حماية أفراد الجماعـة ينبغي أن يكون بتحقيق العدالة الشاملة لا بـالانغلاق

الطائفي.

r . إذا دخل الصراع الطائفي إلى مستوى تمديد الدولة والتمرد، فهناك عدة حلول

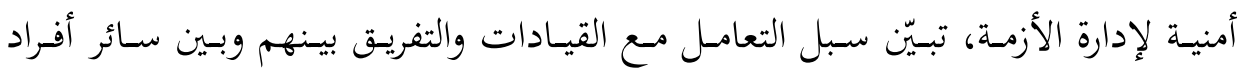

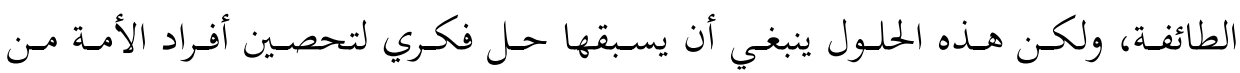

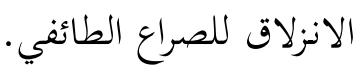

r. أبرزت الدراسة نماذج تراثية ومعاصرة للتعامل مع التنوع داخل المحتمع على نحو

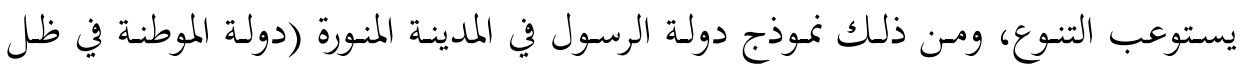

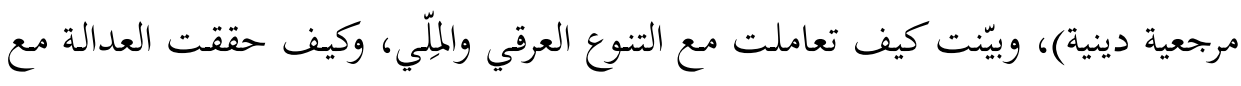

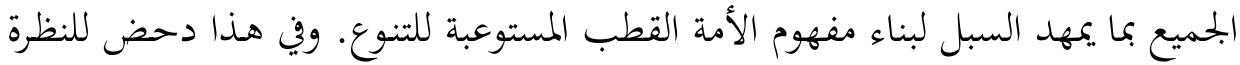
السطحية التي ترى أن قيام دولة المواطنة يستلزم عدم وجود مرجعية دينية. ع ـ كشـفت الدراسـة عـن أهميـة الإفـادة مـن خهـبرات البحتمعـات الإنسـانية الـتي

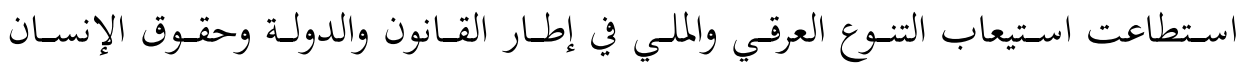

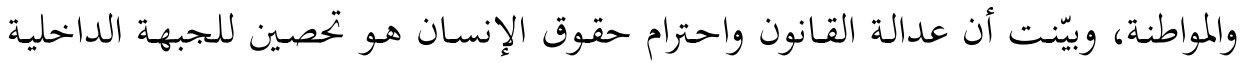

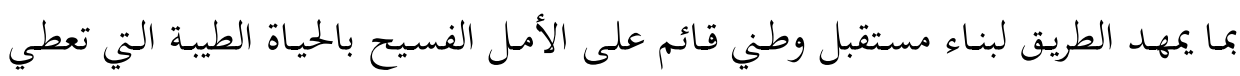

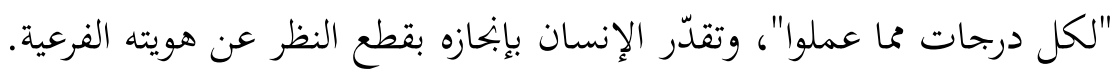
ه. إن الدعوة لإقامة دولة المواطنة على أسس لا دينية بذريعة مواجهة الطائفيـة،

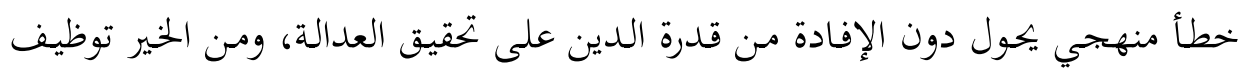
القيم الدينية كالشهادة بالحق في تحصين المجتمع من الطائفية. 7 ـ ثمة حاجة ماسّة لمزيد من الدراسات في سبل تحصين البحتمع من الانزلاق نحو الطائفية وبناء بحتمعات تمهد السبل لأفرادها لتحقيق التنمية. 